IZA DP No. 9252

(Mis-)Predicted Subjective Well-Being Following Life Events

Reto Odermatt

Alois Stutzer

August 2015 


\title{
(Mis-)Predicted Subjective Well-Being Following Life Events
}

\author{
Reto Odermatt
}

University of Basel

Alois Stutzer

University of Basel

and IZA

\section{Discussion Paper No. 9252 \\ August 2015}

\author{
IZA \\ P.O. Box 7240 \\ 53072 Bonn \\ Germany \\ Phone: +49-228-3894-0 \\ Fax: +49-228-3894-180 \\ E-mail: iza@iza.org
}

\begin{abstract}
Any opinions expressed here are those of the author(s) and not those of IZA. Research published in this series may include views on policy, but the institute itself takes no institutional policy positions. The IZA research network is committed to the IZA Guiding Principles of Research Integrity.

The Institute for the Study of Labor (IZA) in Bonn is a local and virtual international research center and a place of communication between science, politics and business. IZA is an independent nonprofit organization supported by Deutsche Post Foundation. The center is associated with the University of Bonn and offers a stimulating research environment through its international network, workshops and conferences, data service, project support, research visits and doctoral program. IZA engages in (i) original and internationally competitive research in all fields of labor economics, (ii) development of policy concepts, and (iii) dissemination of research results and concepts to the interested public.
\end{abstract}

IZA Discussion Papers often represent preliminary work and are circulated to encourage discussion. Citation of such a paper should account for its provisional character. A revised version may be available directly from the author. 
IZA Discussion Paper No. 9252

August 2015

\section{ABSTRACT}

\section{(Mis-)Predicted Subjective Well-Being Following Life Events ${ }^{\star}$}

The correct prediction of how alternative states of the world affect our lives is a cornerstone of economics. We study how accurate people are in predicting their future well-being when facing major life events. Based on individual panel data, we compare people's forecast of their life satisfaction in five years' time to their actual realisations later on. This is done after the individuals experience widowhood, marriage, unemployment or disability. We find systematic prediction errors that are at least partly driven by unforeseen adaptation.

JEL Classification: D03, D12, D60, I31

Keywords: adaptation, life satisfaction, life events, projection-bias, subjective well-being, utility prediction, unemployment

Corresponding author:

Alois Stutzer

University of Basel

Faculty of Business and Economics

Peter-Merian-Weg 6

4002 Basel

Switzerland

E-mail: alois.stutzer@unibas.ch

\footnotetext{
* We are grateful to Thomas Bolli, Thomas Brändle, Adrian Chadi, Christopher Boyce, Bob Cummings, Jan- Emmanuel De Neve, Paul Frijters, Richard Layard, Heather Lench, George Loewenstein, Ori Heffetz, Michael Norton, Andrew Oswald, Frank Pisch, Nick Powdthavee, Drazen Prelec, Eugenio Proto, Hannes Schwandt, Uri Simonsohn, Timothy Wilson, as well as participants at the $6^{\text {th }}$ Bernoulli Workshop in Economics and Psychology at the University of Basel, the Workshop of the Herbert A. Simon Society in Torino, and the research seminars at LSE and Freie Universität Berlin for helpful comments. Reto Odermatt thankfully acknowledges the hospitality of the Center for Economic Performance at LSE, where part of this research was conducted. Data from the German SocioEconomic Panel was kindly provided by the German Institute for Economic Research.
} 


\section{Introduction}

The question whether people correctly predict their future utility levels when facing a major life event poses a challenge for traditional economics. To ensure utility maximizing decisionmaking, neoclassical utility theory is based on two fundamental assumptions: First, people, on average, correctly estimate the probabilities of possible decision outcomes. Second, they know their future preferences. If these assumptions do not hold, people are unable to form correct expectations about the utility that they will derive from alternative situations. They are then likely to make suboptimal decisions, which will, in turn, lead systematically to lower levels of individual welfare compared to a situation with unbiased expectations. Importantly from the perspective of economics, this would undermine the validity of inferring preferences from observed behaviour (see Loewenstein et al. 2003, Kahneman and Thaler 2006, and Frey and Stutzer 2014 for general accounts of utility misprediction). However, so far there is little evidence on how successful people are at making predictions about the development of their future utility in response to major life events. Thus, the following questions emerge: How good are people at predicting the adjustment process after major life events in general? And are any errors driven by changes in circumstances or by unforeseen adaptation?

A first approach to investigate these issues studies how well-being changes around major life events, using data on life satisfaction as a proxy measure for utility. It allows researchers to empirically investigate the claim originally made by Brickman and Campbell (1971) that life is characterized to some extent by a hedonic treadmill, with life events only bringing about transitory changes in hedonic well-being. Indeed, studies show that many life events do not lead to permanent shifts in satisfaction levels, suggesting that people tend to adapt to various changes in life circumstances (e.g., Clark et al. 2008, Oswald and Powdthavee 2008, or recently Clark and Georgellis 2013). Still, even with the insight that people adapt to a certain degree to new life circumstances, it remains an unanswered question to what extent people foresee such adjustment patterns. From the perspective of traditional economics, such an adaptation is only problematic if it is not anticipated in the behaviour of individuals.

A second approach tries to directly examine the accuracy of people's predictions with experiments. Such studies are known as research on affective forecasting in psychology (see, e.g., Wilson and Gilbert 2003 or for a review from an economic perspective Loewenstein and Schkade 1999). The standard procedure to identify forecasting errors is to compare predictions with direct measures of experienced well-being: People are asked to predict how they would feel within a certain time period subsequent to a future event. The participants' responses are then compared with their, or other respondents' actual feelings after experiencing the event. One prevalent finding of such studies is that people tend to systematically overestimate the degree to which they are affected from it! 11

\footnotetext{
${ }^{1}$ In the psychological literature, this tendency is often referred to as the durability bias, which is part of the so-called impact bias which reflects that people tend to overestimate the initial impact and/or duration of an emotional event (Wilson and Gilbert 2003).
} 
Although there are different research designs to identify people's hedonic mispredictions, the literature faces two challenges. First, there is the risk of spurious forecast errors resulting from selection. In order to address it, one can compare the predictions and the realisations for the same individuals. However, this is no trivial task with events such as widowhood which are hard to foresee. Second, generating data on people's forecasts requires asking questions regarding particular events, which makes the event in question salient. This salience potentially contributes to prediction errors (Levine et al. 2012, 2013).

The present study combines the two approaches and tries to circumvent the two challenges by using large-scale long-run panel data on predicted satisfaction with life. We transfer the idea of using evaluative subjective well-being as a proxy for current utility to predicted subjective well-being as a proxy for expected future utility. In order to study people's ability to accurately predict their future satisfaction level in response to major life events, we make use of the German Socio-Economic Panel (SOEP). In this annual survey, participants are not only asked about their individual life satisfaction, but also how satisfied they expect to be in five years' time. The two questions both ask about general evaluations what permits testing the accuracy of people's predictions regarding the long-term impact of life changes without referring specifically to the event. The data track the survey participants' actual life satisfaction as well as their predictions about their future satisfaction around the event in question. This allows a comparison of the expected and the actual longterm consequences after an event. In total we use data from 14 survey waves from 1991 until 2004, consisting of over 180,000 person-year observations. The nature of panel data thereby provides the possibility to use a within-subject (fixed effects) approach to measure potential prediction errors in people's everyday lives.

We extend the identification strategy applied in the literature so far, which captures the development of satisfaction patterns around life changes. Specifically, we estimate two distinct patterns: the first pattern shows the impact of the event on individuals' actual satisfaction; the second pattern shows the impact of the event on the predicted satisfaction. In doing so, we can compare changes in predicted satisfaction right after the event with the actual changes in life satisfaction. The prediction error in this case simply captures the difference between the predicted long-term impact of the event and the actual impact of the event. By looking at the adjustment process, we can show whether and to what extent life events increase prediction errors, and thereby statistically abstract from other sources of prediction errors, in particular individual-specific and age-specific effects. By focusing on the predictions made right after the events, we are able to study to what extent people fail to anticipate the degree to which they adjust to recently experienced changes in life circumstances. With unemployment, disability, widowhood and marriage, we consider a labour market event, a health-related event and, two events involving social relationships. Considering positive and negative events allows us to study potential asymmetries.

The main results show substantial systematic prediction errors, with the discrepancy between predicted and reported satisfaction being greatest with regard to widowhood. In the latter case, 
people, on average, underestimate their future life satisfaction by 0.629 points on the elevenpoint scale. The estimates indicate that people are also unduly pessimistic about their future level of satisfaction after experiencing unemployment or disability. For marriage, the results show that people are, on average, overly optimistic about their satisfaction in five years' time. We find consistent results across a range of alternative specifications. Particularly, we study the robustness of the results regarding the use of different samples, which indicates that our results cannot be explained by sample attrition or sample selection over time.

The overall prediction errors thereby comprise errors that are driven by biased beliefs about future changes in circumstances as well as by unanticipated adaptation. With regard to widowhood, for example, one might underpredict the level of satisfaction experienced five years hence, because one underestimates the probability of finding a new partner or because adaptation is stronger than anticipated. In order to discriminate between these two different sources of prediction errors, we focus on individuals who remain in the respective status for at least five years. By focusing on these individuals, who unfortunately remain in the unfavourable state of widowhood, unemployment, or disability, we can exclude any underestimation of future life satisfaction due to overly pessimistic beliefs about future changes. For marriage, the opposite applies. With the exception of unemployment, individuals who remain widowed, married or disabled show prediction errors in the same direction and that are similar in size as the results of the analysis using the full sample. This provides first evidence that the errors are at least partly driven by unforeseen adaptation.

Two extensions provide further insights. First, we study whether people make successively smaller errors in their utility judgments when repeatedly facing a similar event. If so, this would be consistent with learning having a positive impact on the accuracy of their predictions. We consider people who experience marriage and unemployment more than once. We find that those who remarry or have experienced unemployment more than once tend to have a smaller error on average. These differences are not statistically significant, however. Second, we distinguish between exogeneous and endogeneous sources for the event unemployment by focusing on plant closure as an exogenous event for individual job loss. People who experience unemployment due to this negative shock underestimate the degree to which they regain their initial satisfaction level even more that the average unemployed. This is evidence against the concern that the prediction error of those becoming unemployed is driven by a self-selection of overly pessimistic people into unemployment.

The remainder of the paper is organized as follows: Section 2 presents basic theoretical considerations, a brief survey of the literature, and the general hypotheses. The data and methodology are described in Section 3 and Section 4 presents the main results. Furthermore, we conduct two extensions in Section 5 to provide insights regarding learning and prediction biases in response to an exogeneous event. Section 6 offers concluding remarks. 


\section{Theoretical Considerations and Hypotheses}

When people form predictions about their future well-being, not only do they have to consider the possible states of the world they might live in, but they also have to anticipate the tastes or preferences that will impact their (hedonic) experiences. Consequently, mispredictions can occur regarding their future circumstances as well as their future preferences, both of which will lead to suboptimal decisions according to their own standards Kahneman and Thaler 2006, Frey and Stutzer 2006, 2014, Hsee et al. 2012). Here, the emphasis is on adaptation as a form of endogenous change in preferences. Adaptation is thereby understood that an individual's emotional and evaluative response to a given change in circumstances diminishes over time. For utility predictions to be accurate, it is therefore crucial that people correctly anticipate adaptation. This analytical description of forecasting obviously goes beyond the standard economic model that assumes stable preferences and the rational formation of expectations. In the latter model of rational expectations (Muth 1961), we expect unbiased predictions, and errors that only occur with unforeseen new information, and which are therefore hypothesized to be random. This allows utility maximizing behaviour, given the risk of news shocks. In the following, we first briefly characterize the prediction problem in a framework that captures both the anticipation of changes in circumstances as well as of adaptation. Second, before we derive our basic hypotheses, we refer to previous evidence on adaptation to life changes, affective forecasting, and the prediction of future well-being in general.

\subsection{A Simple Framework of Utility Prediction After Life Events}

The two sources of errors in utility predictions relating to changes in circumstances and preferences can be summarized in a simple framework. In some future period $t+k$, individual $i$ experiences the utility

$$
\begin{aligned}
U_{i, t+k} & =U_{i}\left(x_{i, t+k}, S_{i, t+k}\right) \\
& =U_{i}\left(x_{i, t}, S_{i, t+k}\right)+\beta U_{i}\left(\Delta x, S_{i, t+k}\right),
\end{aligned}
$$

depending on the initial state of the world $\mathrm{x}_{i, t}$, the potential change in circumstances $\Delta \mathrm{x}$ that materialize or not, i.e., $\beta=\{0,1\}$, and the state of preferences $\mathrm{S}$ in period $\mathrm{t}+\mathrm{k}$. We assume separability with regard to the change in circumstances. In the context of this paper, $\Delta \mathrm{x}$ can either be a negative change in the case of the switch from being married to being separated, or a positive change in the case of leaving the state of widowhood, unemployment or disability by finding a new partner, a job or by convalescing, respectively.

For the formulation of predicted utility we follow the model of a simple projection bias in Loewenstein et al. (2003), where the predicted utility depends on the factor $\alpha=[0,1]$ that expresses the extent to which individuals correctly anticipate their adaptation or change in preferences. In our simple extension, the prediction further depends on the anticipation of the change in circumstances. The predicted probability of a change in circumstances is reflected by the factor 
$\beta^{\prime}=[0,1]$. In period $t$, individual i's predicted utility is given by

$$
\begin{aligned}
P U_{i, t}= & (1-\alpha) U_{i}\left(x_{i, t}, S_{i, t+k}\right)+\alpha U_{i}\left(x_{i, t}, S_{i, t}\right) \\
& +(1-\alpha) \beta^{\prime} U_{i}\left(\Delta x, S_{i, t+k}\right)+\alpha \beta^{\prime} U_{i}\left(\Delta x, S_{i, t}\right) .
\end{aligned}
$$

The anticipation of adaptation can vary between $\alpha=0$, i.e., adaptation is fully foreseen and $\alpha=1$, i.e., adaptation is not anticipated. In the latter case, the prediction is made on the basis of the current state of preferences $\mathrm{S}_{i, t}$ instead of $\mathrm{S}_{i, t+k}$, neglecting the change in preferences due to adaptation. The same applies to the predicted utility that is derived from the potential change in circumstances, weighted by the subjective probability that such a change occurs.

The prediction error, i.e., the difference between the utility predicted in period $t$ and actual utility in period $\mathrm{t}+\mathrm{k}$, thus amounts to

$$
\begin{aligned}
\operatorname{error}_{i, t}= & P U_{i, t}-U_{i, t+k} \\
= & \alpha\left(U_{i}\left(x_{i, t}, S_{i, t}\right)-U_{i}\left(x_{i, t}, S_{i, t+k}\right)\right) \\
& +\left(\beta^{\prime}-\beta\right) U_{i}\left(\Delta x, S_{i, t+k}\right) \\
& +\alpha \beta^{\prime}\left(U_{i}\left(\Delta x, S_{i, t}\right)-U_{i}\left(\Delta x, S_{i, t+k}\right)\right) .
\end{aligned}
$$

The resulting error consists of three terms. The first term $\alpha\left(\mathrm{U}_{i}\left(\mathrm{x}_{i, t}, \mathrm{~S}_{i, t}\right)-\mathrm{U}_{i}\left(\mathrm{x}_{i, t}, \mathrm{~S}_{i, t+k}\right)\right)$ captures the utility differential due to the change in preferences that is weighted by the factor $\alpha$ for the anticipation of adaptation. The bigger the change in preferences is, and the less this change is anticipated $(\alpha>0)$, the bigger the error (that can be either positive or negative) will be. In the case of unanticipated adaptation to the negative event of unemployment, for example, this term would negatively contribute to the error, and thus reflect underestimated utility. The second term $\left(\beta^{\prime}-\beta\right) \mathrm{U}_{i}\left(\Delta \mathrm{x}, \mathrm{S}_{i, t+k}\right)$ picks up the contribution to the bias that emerges if the potential change in circumstances is not correctly anticipated. For instance, in a situation where a newly unemployed person expects some chance to find a new job $\left(\beta^{\prime}>0\right)$, but where this positive change in circumstances does not materialize $(\beta=0)$, an overestimation of future utility occurs. Hence, this term either countervails or augments the prediction error due to the individual's omission to consider possible adaptation. The third term $\alpha \beta^{\prime}\left(\mathrm{U}_{i}\left(\Delta \mathrm{x}, \mathrm{S}_{i, t}\right)-\right.$ $\left.\mathrm{U}_{i}\left(\Delta \mathrm{x}, \mathrm{S}_{i, t+k}\right)\right)$ also captures a contribution to the prediction error caused by a change in the individual's preferences; this, however, only relates to a change in circumstances and only to the extent to which that change is expected. This latter term captures the correction of the second term to the extent that the two other sources of the bias interact; i.e., the utility prediction for the expected change in circumstance was made under wrong beliefs about the future state of preferences.

In order to illustrate how the framework captures a maximal prediction error, imagine the utility forecast of a newly unemployed person. If this individual expects to remain unemployed and to continue to feel the shock of redundancy in the future, he or she misperceives his or her future situation by failing to consider potential adaptation to the status of unemployment as well as 
potential re-employment. In formal terms, for $\alpha=1$ and $\beta^{\prime}=0$, the prediction error is maximal and future utility is underestimated in this example; first due to an omission to consider any adaptation, and, second, due to a failure to consider a possible improvement in circumstances.

In the empirical analysis, first, the average prediction errors are estimated for people who forecast their well-being after major life events. The estimates, in turn, incorporate all three terms of equation (3). Second, in order to discriminate between the different sources of prediction errors highlighted in equation (3), we only consider the prediction errors of people who do not experience a change in circumstances. These people can only overestimate a change in circumstances, i.e., $(\beta$ ' $-\beta)>0$. Accordingly, for all four studied life events the prediction error that results from unanticipated adaptation is partly countervailed by the error due to the overestimation of a change in circumstances. The net effect can thus be considered a lower bound for any misprediction attributable to the effect of (partially) failing to consider any adaptation.

\subsection{Previous Evidence on Adaptation and the Prediction of Subjective Well- Being}

While it seems self-evident that people's well-being must change if circumstances change, it is less clear to what extent such changes persist when the new conditions stabilize. There is a strong scientific claim of hedonic relativism in psychology (for a discussion, see Powdthavee and Stutzer 2014 and the other chapters in Sheldon and Lucas 2014). This view is related to the prominent work by Brickman and Campbell (1971), which proposes the idea of a hedonic (or happiness) set point due to the process of adaptation: People get used to a new situation or repeated stimuli and thereby return to their innate level of experienced well-being. The authors combined their claim with empirical evidence based on tiny cross-section samples Brickman et al. 1978). Their conclusions provoked substantial empirical research on adaptation (for an early review, see Frederick and Loewenstein 1999). In the meantime, it is standard practice to conduct longitudinal analyses and to study profiles of reported subjective well-being around life changes. This allows for individual-specific level effects to be taken into account when exploring adaptation. Applications refer to various events such as marriage, widowhood, divorce, birth of a child, separation, unemployment, crime victimization, and disability (see, e.g., Clark et al. 2008, Frijters et al. 2011, Lucas 2007 and Clark and Georgellis 2013 for studies involving multiple events, and Luhmann et al. 2012 for a meta-analysis). Particularly for widowhood, these studies find pronounced satisfaction profiles, where the large negative effect of the death of the spouse vanishes entirely after two to three years, which corresponds to a pattern with full adaptation. For marriage, an early study by Lucas et al. (2003) interprets the increase in life satisfaction before marriage and the decline afterwards in reference to the set point model. A complementary panel analysis by Stutzer and Frey (2006) finds a similar pattern over time, but a remaining positive well-being differential for the married. Moreover, they present evidence of happy people selecting into marriage, which underscores the importance of using longitudinal research designs to study adaptation. For unemployment, evidence suggests limited adaptation 
(e.g., Kassenboehmer and Haisken-DeNew 2009 in their study of people who experience a layoff due to plant closure). Research on disability finds partial adaptation that is more pronounced for people facing comparatively lower levels of legally attested disability (Oswald and Powdthavee 2008). Overall, the evidence suggests that there is adaptation to changes in circumstances due to major life events. This adaptation, however, differs across events and is far from complete for some of them.

Given the evidence that people to some extent adapt to changing circumstances with respect to subjective well-being, the question emerges whether such adaptation is anticipated or not. We investigate this question below by studying the accuracy of people's predictions after a major life event. Previous evidence reports that individuals are not good at foreseeing how much utility they will derive from possible future states of the world (for a review, see Wilson and Gilbert 2003 and most recently Wilson and Gilbert 2013). Research on affective forecasting shows, in particular, that people tend to overestimate their reactions to specific events: The experience of an event is usually embedded in other daily life events that influence an individual's general level of well-being. However, people tend to give these other events too little weight at the time of their prediction. Another source for errors in predicting emotions is that people underestimate their ability to successfully cope with negative events ${ }^{2}$ The general notion is that people usually have biased expectations about the intensity and duration of their emotional responses, in the sense that the emotional impact is often less harsh than predicted, because people adapt to the new circumstances more easily than they had anticipated. However, the explanation based on focalism, i.e. "the tendency to focus on one event and neglect to consider how emotion will be mitigated by the surrounding context" (Lench et al.|2011, 278), is also the origin of an important methodological criticism of typical study designs. When people are asked about their forecasts regarding specific aspects of their future status, a focus or salience is induced that might itself create a bias in affective forecasting (see the discussion between Levine et al. 2012, 2013 and Wilson and Gilbert 2013).

In our approach, we draw on forecasts that do not ask about expected satisfaction with specific circumstances. Instead, we consider people's general predictions of their future life satisfaction. In a longitudinal study, these assessments can then be put in comparison to current reported satisfaction with life when time arrives. Frijters et al. (2009) apply this approach to study the accuracy of forecasts in the New German Laender after the fall of the Berlin Wall, but before reunification and find evidence for clear initial over-optimism. Based on the same panel data for Germany, Schwandt (2013) and Lang et al. (2013) document a systematic life-cycle pattern where young people have overly optimistic expectations about their future life satisfaction, while older people gradually become overly pessimistic about their future well-being. Schwandt argues that this pattern in unmet expectations partly drives the U-shape in the relationship between age and well-being.

\footnotetext{
${ }^{2}$ The phenomenon that people are generally unaware of the influence that their psychological immune system has in reducing the negative affect is known as immune neglect in the psychological literature (e.g., Gilbert et al. 1998). This mechanism works complementarily to the tendency to overrate the impact of any single factor. Kahneman et al. (2006) refer to the latter tendency as focusing illusion.
} 


\subsection{Hypotheses for Prediction Errors After Major Life Events}

Predictions about the direction of errors in forecasts of future subjective well-being are difficult to draw, as these errors have potentially countervailing sources. People might systematically err in terms of future preferences as well as circumstances. In our framework, this is reflected by $\alpha$, i.e., the degree adaptation is anticipated, and the extent to which changes in circumstances $\Delta \mathrm{x}$ are foreseen. For the investigation of preference change or adaptation, we rely on the most general claim in the literature, i.e., that people to a large extent neglect these aspects when forming their predictions $(\alpha>0)$. Combining previous evidence that at least some adaptation occurs regarding all the four life events that we explore (widowhood, marriage, unemployment and disability) with the claim that people tend to disregard considerations of adaptation, leads to the following hypothesis:

People are overly optimistic with regard to their future life satisfaction after marriage and overly pessimistic after becoming widowed, unemployed or disabled.

This effect is, furthermore, expected to increase in the degree of adaptation. Misprediction is thus hypothesized to be at a maximum if full adaptation to an event occurs but is not anticipated $(\alpha=1)$. In contrast, it is at a minimum if there is no adaptation, or adaptation is perfectly foreseen $(\alpha=0)$. However, the basic hypothesis only holds when people, on average, correctly anticipate changes in their circumstances after the event $\left(\beta^{\prime}=\beta\right)$. The predictions for the overall effect may be different if people's anticipations of circumstances are systematically wrong; i.e., if people misperceive the probability of a status change $3^{3}$ In particular, if the expected probability of a status change is lower than the actual probability $\left(\beta^{\prime}<\beta\right)$, both sources contribute to the error in the same direction. In the latter case, we cannot empirically separate the components of equation (3). In order to gain lower bound estimates of the potential misprediction of adaptation, we study, inter alia, subsamples in the empirical analysis which only include people who do not experience a change in their status. These people cannot be overly optimistic in terms of the stability of their marriage or overly pessimistic regarding their re-employment, their recovery, or their prospects of finding a new partner. If they are still too optimistic in terms of future life satisfaction for marriage and too pessimistic for the negative events, unforeseen adaptation is a likely reason.

\footnotetext{
${ }^{3}$ There is indeed evidence for an optimism bias; i.e., an overestimation of the likelihood of positive events (see, e.g., Sharot 2011 for a review). Newly-weds might thus underestimate the risk of divorce, supporting an overestimation of future life satisfaction. In contrast, unemployed people might overestimate their re-employment prospects, thereby countervailing overly pessimistic forecasts of their well-being (or even reversing them into overly optimistic forecasts). The extent to which widowed and disabled people consider they are likely to find a new partner or recover from their mental or physical impairment is not as easy to determine.
} 


\section{Data and Methodology}

\subsection{Data Description and Event Samples}

Our empirical analysis is based on individual-level panel data from the German Socio-Economic Panel (SOEP), an extensive representative survey of the population in Germany. Since 1984 people are surveyed and asked a wide range of questions regarding their socio-economic status and their demographic characteristics. In the survey, subjective well-being is reported by answering the question: "How satisfied are you with your life, all things considered?". In some years, people are subsequently asked "And how do you think you will feel in five years?". For both questions, respondents are asked to answer the question according to a scale from 0 meaning "completely dissatisfied" to 10 meaning "completely satisfied". Over thirteen consecutive years between 1991 and 2004 both questions were asked in the survey. Thereby, item non-response is less than half a percent for actual and less than two percent for predicted satisfaction. The resulting data provide the information for the two key variables used in this study to investigate potential prediction errors.

We focus our analysis on four major life events: widowhood, marriage, unemployment, and disability. With widowhood and marriage, we consider one negative shock and one positive life event, respectively. Unemployment refers to a major individual labour market event, and disability captures a serious negative health shock which is also related to the work realm. As indicators for the events, we follow the strategy presented in Clark et al. (2008) and use the year-to-year changes of the respective statuses for each individual. For example, if the marital status of an individual changes from married to widowed, it indicates the first observation after the event of widowhood. The same strategy applies for the other three event types. For unemployment, the status change to registered unemployment is decisive. Disability is defined on the basis of a scale which indexes the gravity of the legal attested disability from 0 to 100 , where a value of more than 30 categorizes the individual as being disabled. In our baseline analysis, we only consider the first time that the respective status change occurs within the sample period of an individual. Hence, we exclude respondents if we have no observation indicating the point of time when they changed their status (left-censored spells), as we are consequently unable to calculate how long they have been, e.g., widowed. We further require a full record of observations without missing years. This assures that we observe all status changes. For the labour market-related events of unemployment and disability, we further restrict the sample to individuals under the age of 60 and who are not about to retire within the next five years. This prevents expectations about retirement from systematically influencing predicted life satisfaction. Besides only using respondents who are older than 16 years of age, we have no further age restrictions on widowhood or disability. We require non-missing observations for actual and predicted satisfaction with life, as well as for all the control variables. This assures the same sample across the two key satisfaction measures. Consequently, we restrict the sample to the period from 1991 until 2004. These restrictions leave us with a final sample of 183,727 
observations for widowhood, 64,624 for marriage, and 143,302 for unemployment. These samples include both, people who have experienced the event in question and people who have not, but might experience it 4 For disability, information on the status of individuals is not available in 1993. Therefore, we impute the information of the following year if a legally attested disability is indicated in the year before and after 1993. We exclude the 102 cases where this information is not given. Our final sample for the analysis of disability contains 143,184 observations.

\subsection{Descriptive Statistics and Evidence}

Table 1 provides a summary of the number of observations of individuals who experience widowhood, marriage, unemployment, or disability for the respective years before and after that event. As noted, individual observations are included irrespective of whether they change their status again, e.g., by finding a new job after becoming unemployed 5 The decreasing number of observations after the events thus derives solely from missing values in any of the variables and from panel attrition. The uneven number of observations in the year before and after the event is driven by the exclusion of observations around the event due to the age- and year-specific sample restriction.

[Table 1 about here]

Descriptive statistics are presented in Table A.1, exemplarily for the sample generated to study widowhood. All the listed characteristics will serve as control variables in the respective analysis. To initially obtain descriptive evidence, Figure 1 plots the mean development of the actual life satisfaction and the predicted life satisfaction around the status changes.

\section{[Figure 1 about here]}

People who become widowed, on average, are pessimistic about their life prospects. This is revealed by predicted levels of life satisfaction being lower than current levels of life satisfaction in the years prior to the event. Given that the average widowed person is relatively old, this

\footnotetext{
${ }^{4}$ Including people who are at risk of experiencing an event in question allows estimating the coefficients of our control variables more precisely. Depending on the event studied, people remain in the sample, on average, for 5.4-5.9 years. Robustness tests regarding the selection of the sample and panel attrition are considered in Section 3.5. The relatively low number of observations for marriage derives from the restriction to people who can potentially marry. We thus exclude those individuals who are already married when being surveyed the first time. This applies to more than 60 percent of the sampled individuals.

${ }^{5}$ This sample selection in the baseline analysis is chosen, because we are interested in the general ability of people to foresee their adjustment process after an event. In terms of our model we thereby estimate the error consisting of all three terms of equation (3). This focus contrasts with previous research studying patterns in subjective well-being around life events; as for example, the study by Clark et al. (2008) or Clark and Georgellis (2013), who exclude those people who leave the status in question from the sample (e.g., unemployed people who find work again). Such a sample restriction would generate a systematic selection effect in our study, as the focus would be, for example, on unemployed people who remain unemployed. This would thus be a group who only experienced the negative realisations of potential labour market transitions, potentially making them look like terribly inaccurate forecasters.
} 
observation is consistent with previous findings that older people tend to be pessimistic regarding their future life satisfaction (Schwandt 2013). In the first interview after experiencing the event, these people tend to be slightly optimistic. However, they are not optimistic enough, when comparing the prediction of their life satisfaction of 5.80 in year zero for year five to their actual life satisfaction five years after the event of 6.84. Around marriage, people are optimistic regarding their future life satisfaction. The high expectations right after marriage are clearly not borne out when looking at the slightly falling pattern in actual life satisfaction. Predicted and actual life satisfaction seem closer in the case of unemployment and disability when comparing the prediction in year zero and the realisation in year five. For all the four events, we observe that the impact of the event on predicted satisfaction is weaker in general than it is on actual satisfaction. This suggests that people expect the impact of the event to partially fade out, although the prediction for their satisfaction in five years is influenced by the event in the same direction as their current satisfaction.

Another descriptive way to approach the question of whether life events increase the average prediction error is presented in Figure 2. It shows the distribution of the errors in a histogram. These errors represent the difference between the predicted satisfaction with life and the actual satisfaction five years later.

[Figure 2 about here]

For all the events, two distributions of the prediction errors are plotted. The light grey histograms show the distribution for the samples restricted to people who might but do not experience the event in question. The distributions indicated by the coloured solid lines show the prediction errors involving only the predictions in the first year after the event. Negative values on the horizontal axis represent underpredicted satisfaction. This indicates that people's expectations were lower than the actual satisfaction five years later, i.e., they were overly pessimistic (or not sufficiently optimistic) about the future. In contrast, positive values are a sign of forecasts that were overly optimistic. Interestingly, the histograms reveal that people make prediction errors in both directions. After every event, there are people who think that they will be more satisfied in five years time than they then actually are, and vice versa. Still, in the first year after being widowed, people tend to underestimate their future satisfaction to a larger extent than an average person who has not lost his or her spouse. The same picture emerges for the other two negative events of unemployment and disability, though less pronounced. For the positive life change marriage, we observe the opposite. People tend to make more positive prediction errors meaning that they were overly optimistic the year after their marriage. The systematic deviation in the distribution of errors between those people who experience an event and the full sample of those who are at risk of experiencing that event presents first descriptive evidence that people make bigger mistakes when predicting their adjustment process after major life changes compared to the years without such changes. 


\subsection{Empirical Strategy}

A descriptive analysis based on raw discrepancies between actual and predicted life satisfaction has clear limitations, as individuals who experience an event might share underlying sociodemographic characteristics related, for example, to overly pessimistic predictions. Moreover, individual-specific differences in optimism or pessimism might drive the dispersion of the errors. Such aspects of selection and heterogeneity need to be taken into account in order to properly identify prediction errors regarding the adjustment process after major life events. We do this and extend the established identification strategy that is applied when the development of satisfaction patterns around life changes is studied. In this latter research, separate time-dummies for the years around the events are used to capture the effects of these life changes on subjective well-being before and after the individual's status changes. This allows us to estimate the patterns shown in Figure 1 in a panel regression framework.

Our strategy comprises three steps. In a first step, we estimate the pattern of the impact of an event on the predicted satisfaction in five years. The average impact of an event at the time of the first observation after it occurred then includes the anticipated adjustment. In other words, it reflects the expectations regarding the long-term impact of the event. If people believe that they will return to their old satisfaction level within five years, the event should in turn not affect predicted satisfaction. In a second step, we estimate the actual changes in life satisfaction around the event. Comparable to the strategy used by other studies, the estimations of actual life satisfaction as the dependent variable show how satisfaction changes around major life events. We thus estimate the full pattern of the actual impact of the events, particularly also for the period five years after the events. In a third step, the expected changes can then be compared with the actual impact of an event five years after the event. This provides us with a direct measure of the prediction error associated with the events, conditional on the average individual-specific errors three years or more before the event.

Practically, for the first two steps, we estimate models of the following form:

$$
\begin{aligned}
& P S_{i t}=\alpha_{i}+\sum_{j=-3}^{6} \theta_{j} E_{i t}^{j}+\beta^{\prime} \mathbf{X}_{i t}+\varepsilon_{i t} \\
& L S_{i t}=\alpha_{i}+\sum_{j=-3}^{6} \theta_{j} E_{i t}^{j}+\beta^{\prime} \mathbf{X}_{i t}+\varepsilon_{i t}
\end{aligned}
$$

The two equations only differ in terms of the dependent variable. $P S_{i t}$ stands for the predicted life satisfaction of individual $i$ at time $t$, and $L S_{i t}$ stands for the realized actual life satisfaction of individual $i$ at time $t . \mathbf{X}_{i t}$ is a vector of individual controls. The main explanatory variables are given by the series of dummy variables $E_{i t}^{j}$ indicating the number of years $j$ before and after the event. The first dummy captures observations two to three years before the event. The last dummy captures the reports of people who experienced the event six or more years 
previously. This leaves all the years prior to at least three years before the event as the reference category. Importantly, we further include individual fixed-effects $\alpha_{i}$, which provide us with within-individual estimates. This controls for any time-invariant characteristics, and implies that the partial correlations are only based on variation within the same person over time. It thus rules out that individual-specific optimism or pessimism drives the differences between predicted and experienced life satisfaction. Still, the control strategy is not sufficiently restrictive if such optimism or pessimism is not constant over time, because, for example, older people become pessimistic. Therefore, the vector of control variables includes age-specific fixed effects that capture changes in our dependent variables that are common for a particular age group. Time-fixed effects are further included to control for systematic changes over time common to all individuals. Region-fixed effects control for regional characteristics that might be correlated with our variables of interest. Standard errors are clustered at the individual level. This takes into account that idiosyncratic errors $\varepsilon_{i t}$ might be serially correlated and in turn understated (Bertrand et al. 2004). In short, these first two steps provide the profiles for life satisfaction and predicted satisfaction around life events conditional on individual-specific reference periods, ceteris paribus.

In a third step, we can compare the expected long-term impact of an event with the actual impact of the event on life satisfaction. With respect to our estimation models, we calculate the difference between the coefficient $\theta_{0}$ of model (4) and $\theta_{5}$ of model (5) to derive the average change in individual prediction errors due to an event. We use exactly the same observations across the two estimation models. Any gap between prediction and realisation can therefore not be influenced by any year- and person-specific differences between the samples. With a reference period of at least three years before the event, the calculated difference is conditional on the average prediction errors of the respective individuals at a time the event is unlikely to be anticipated. The identifying assumption is thus that people's interpretation of the scales does not change due to the event. This condition is necessary to hold so that the average prediction error of an individual in the period prior to three years before the event can serve as a valid counterfactual.

\section{Estimation Results}

\subsection{Prediction Errors Following Life Events}

Table 2 presents the results for the estimated models outlined in equation (4) and (5) ${ }^{6}$ For all four events, we show the regression results for the two dependent variables side by side. Columns labeled PS indicate estimates with predicted satisfaction as the dependent variable. Columns labeled LS show the estimates with current life satisfaction as the dependent variable. The latter estimates are comparable to the results in the literature exploring satisfaction profiles around life events.

\footnotetext{
${ }^{6}$ A full estimation output including the control variables is reported in Table A.2.
} 
[Table 2 about here]

Column II reveals that widowhood has a large negative short-term effect on people's life satisfaction. Compared to their base-line level of subjective well-being three or more years prior to the event (i.e., the reference period), reported satisfaction is 1.231 points lower. It also reveals that the effect fades out over time. After three years, the difference is close to zero and not statistically significant anymore. This also holds five years after the event. However, the estimation results in column I indicate that people, on average, expect their life satisfaction in five years' time to be substantially negatively affected by the loss of their spouse. The predicted life satisfaction is 0.611 points below the level during the reference period. In the second year, a negative effect for the future is still predicted, though of a smaller magnitude.

Based on the estimates in Table 2, we have an empirical comparandum to the theoretical prediction error, namely the difference that results when the actual impact (the coefficient for 5-6 years in specification II) is subtracted from the predicted impact (the coefficient for 0-1 year in specification I). In the case of widowhood, the estimates indicate a statistically significant difference of -0.629 on the eleven-point satisfaction scale 7 In sum, the negative expectations are too pessimistic as revealed by the sizeable negative prediction error. This finding is in line with our hypothesis that people underestimate adjustment processes that counteract shocks to subjective well-being. For marriage, a similar but less pronounced pattern arises with opposite signs and a smaller prediction error of 0.133 points. Newly-wed couples experience a period of life satisfaction above their reference level (coef. for $0-1$ year $=0.344$ in specification IV) and predict this higher level to hold at least partly over time (coef. for 0 - 1 year $=0.203$ in specification III). However, this evaluation turns out to be too optimistic with life satisfaction being only slightly above the reference level after 5 to 6 years.

For the two shocks related to the work realm, unemployment and disability, prediction errors resulting from overly negative expectations are found consistent with the main hypothesis. However, the two events differ from the previous ones, as people do not fully return to their original satisfaction level, even after 6 years. This observation is in line with the literature that reports no full adjustment for individuals who remain in the respective status. However, with our sample, we measure the initial effect of the event for all the people irrespective whether they remain disabled or unemployed. The finding from the literature that people do not fully adjust to these two events therefore holds even for a sample that does not exclude the people who overcome the adverse states. Moreover, individuals tend to underpredict the degree to which they regain their original satisfaction level after being confronted with the negative impact of the events. Regard-

\footnotetext{
${ }^{7}$ As the estimates are based on the same samples, the estimators are stochastically not independent from each other. This requires that the covariance of the two regressors is taken into account when testing the difference between two regressors across the two models. We do so by combining the regression results for the separate estimations by applying the stacking method described in Weesie (1999) (implemented in Stata with the -suestpostestimation command). This allows storing the parameter estimates and associated (co)variance matrices into one parameter vector to get a simultaneous (co)variance matrix of the sandwich/robust type. Applying this strategy, any difference in the effects between the estimations can then be derived by calculating the linear combination of the two coefficients (e.g., [PS]lag01 -[LS]lag56).
} 
ing unemployment, they underpredict their future satisfaction by -0.218 points, and regarding disability they underpredict it by -0.200 points.

In order to simplify the interpretation of the regression coefficients provided in Table 2, we present the estimation results graphically in Figure 3. The black solid line shows the effects on current satisfaction, while the red x-marks capture the effects on predicted satisfaction. In order to facilitate the approximation of the prediction error, a red dotted line is included to assign the event's effect on the predictions right after the event (0-1 year after the event) across the time periods up to period five (5-6 years after the event). The prediction error is thus reflected in the difference between the dotted line and the black solid line in period five.

[Figure 3 about here]

As noted above, the effects of the events on the actual satisfaction levels are much larger than on the predicted satisfaction levels. While the individuals thus might anticipate some adjustment, the figures suggest that their predictions for their long-term adjustment are too conservative. This holds even for the short term. Figure 3 shows that the deviations of actual satisfaction from the baseline satisfaction level are smaller than they are from the predicted long-term satisfaction level. This is indicated by the black solid line that crosses the red dotted line already after one period in the case of widowhood and marriage (or two in the case of unemployment).

\subsection{Robustness Regarding Alternative Samples}

The estimations in Table 2 include the individuals who experienced the respective events in question and individuals who did not experience them, but potentially could have (i.e., people who did not lose their spouse or job, or did not marry or become disabled). Based on the extended samples, the coefficients of our control variables are more precisely estimated, which in turn increases the efficiency of the estimation of our key coefficients. However, this requires that the statistical relationship between the control variables and the dependent variables is the same across people who experience the event and people who do not. Therefore, in a first robustness check, we conduct the regressions as in Table 2, based on samples of people who all experience the respective events. The number of observations for the regressions is reduced to those listed in Table 1. With fewer observations, we expect the standard errors to increase in these estimates compared to the main specifications with the full sample. The size and the direction of the calculated prediction errors should remain similar.

The second robustness check addresses concerns regarding attrition in our baseline sample. Due to sample restrictions and panel attrition, the coefficient for the variable 0 - 1 year in the specification for predicted satisfaction PS is not based on exactly the same observations as the coefficient for the variable 5-6 years in the specification for current satisfaction LS. In an unbalanced panel, people might leave the sample between the first and the sixth period after the event. As a consequence, for some people we only observe a prediction of their life satisfaction 
without its corresponding realisation, or vice versa. If panel drop-outs are systematically related to how people are affected by the event, the estimated prediction errors are potentially affected by panel attrition. For example, someone could be severely affected by an event and in turn might correctly predict low future satisfaction. If this person is more likely to drop out, the effect on actual satisfaction five years after the event might look too rosy. This kind of selection effect would lead to a spuriously bigger prediction error. Therefore, we also estimate the patterns based on those individuals for whom we have both, a prediction of life satisfaction right after the event and a realisation five years later. Accordingly, we focus on events that occur between 1991 and 1999. We are thereby able to follow the adjustment process for at least five years for all the affected individuals. The specifications in Table 2 are thus re-estimated with a reduced number of individuals experiencing the event (in comparison to the numbers in Table 1), amounting to 4,200 observations to identify the effect of widowhood, 10,591 for marriage, 14,521 for unemployment, and 2,719 for disability.

Figure 4 presents a summary of the resulting prediction errors for the baseline samples, as well as the samples generated for the robustness checks. The 90 percent confidence intervals are indicated. For all the events, the prediction errors derived from the robustness checks show the same sign and are not statistically significantly different from the main specification. As expected, the standard errors, and hence the confidence intervals, are slightly bigger for the complementary estimates. The effects for widowhood and unemployment remain similar in size and statistically significant. For marriage and disability the prediction errors are not statistically significant anymore once only those individuals are considered, for whom the prediction and the realisation is observed. In the case of marriage, the error is also statistically insignificant when the sample is restricted to people who experience the event. The statistically weaker results might not come as a surprise as the respective estimations rely on less observations. Given that the prediction errors derived from the alternative samples are similar in size, it is unlikely that the main findings are the result of sample selection and attrition. Accordingly, our preferred estimation relies on the extended sample providing us with the most precise point estimates.

[Figure 4 about here]

\subsection{Evidence for the Underestimation of Hedonic Adaptation}

Our findings so far reveal systematic prediction errors after major life events. The patterns in reported subjective well-being after the events suggest that the measured prediction errors could be interpreted to some extent in terms of unanticipated adaptation. However, prediction errors may as well occur due to unanticipated changes in circumstances. For example, people who lost their spouse and thought that they would remain solitarily may - unexpectedly - find a partner. Regarding unemployment, people who expect to remain unemployed due to poor job prospects, and who are thus pessimistic regarding their future satisfaction, may nevertheless find a new job. 
In order to test for the underestimation of adaptation (in contrast to changing circumstances) as a reason for prediction errors, we study individuals who remain in their status after a life event. As people's expectations about changes in their circumstances are not elicited, we cannot include respective measures in our estimations. However, a focus on those who do not change their status allows us to conduct a test that can be interpreted as identifying a lower bound for the misprediction of adaptation.

The experimental scenario explaining our strategy runs as follows (see also Subsection 2.1): Individuals form a well-being forecast based on the subjective probability $\beta$ ' that they will leave their status (i.e., that they will find a new partner, get divorced, find employment, or regain their health) and the probability $1-\beta$ ' to remain in the status. With a correct prediction of adaptation, those who remain in their status (realisation of $\beta=0$ ) are therefore likely to be too pessimistic regarding marriage and too optimistic regarding widowhood, unemployment, and disability. If the data show the opposite pattern - over-optimistic regarding marriage and overpessimistic regarding the other events - this cannot be explained by an inaccurate expectation of the probability of leaving of the status. In the case of widowhood, for example, people who remain solitarily can only have erred in not finding a new partner. However, in the case of over-pessimism, unanticipated hedonic adaptation would be a consistent explanation. Note that this strategy allows us to deal with mispredicted probabilities for changing circumstances in the domain of the respective life event. There might well be mispredictions of probabilities also in other life domains. However, we do not think that they are systematic beyond our controls. As before, we control for person- and age-specific systematically misperceived probabilities by the inclusion of individual fixed effects as well as age-specific fixed effects.

The regression analysis of our test is based on the same sample as the one used for the main analysis presented in Table 2. However, we estimate separate patterns of actual and predicted life satisfaction for those individuals who leave their status after a life event and for those who remain in their respective status for at least five years. By using this specification, we maintain the same set of reference observations as in the former regressions (i.e., the observations at least three years before the event of all who will experience the event), as this allows us to compare the effect sizes directly. The criterion applied to categorizing individuals as remaining disabled requires that the gravity of their incapacity is evaluated to be above the threshold index of 30 , and that the degree of their disability has made no improvement during the first five years after suffering the handicap. Table A.3 lists, for each event type, the number of observations before and after the events for those who remain in the respective status for at least 5 years 8 Note that the number of observations in the case of disability and especially of unemployment is rather small.

Figure 5 presents the estimation results graphically (for a numerical output, see Table A.4). In

\footnotetext{
${ }^{8}$ This is the number of observations after the age- and year-specific sample restrictions and missing values in the control variables are taken into account. Without these restrictions, the sample would include the same number of observations spanning the period from 1-0 years before the respective event to 5-6 years after it. In the raw data, the number of individuals who keep their status is 609 for widowhood, 1,675 for marriage, 156 for unemployment, and 404 for disability.
} 
the cases of widowhood and disability, even the people who remain in their status are overly pessimistic in forecasting their life satisfaction in five years time. For disability, the calculated prediction error of -0.400 is even larger than if calculated for everybody who experiences the event. With an error of -0.622 for widowhood, the size is almost identical with the result in Table 2. Figure 6 compares the average prediction errors made by all the individuals who experience the respective events and by those who remain in the corresponding status for at least five years. For marriage, the forecasts remain overly optimistic (with an effect size similar to the finding for all the people who marry). The effect is, however, no longer statistically significantly different from zero. Overall, the findings suggest that in the case of the three life events, widowhood, disability and marriage, the observed average prediction errors are to a large extent driven by the underestimation of adaptation (and not by prediction errors due to unanticipated changes in circumstances).

[Figures 5 and 6 about here]

In the case of unemployment, those individuals who remain unemployed are observed to be too optimistic regarding their future life satisfaction. Due to the small number of individuals who experience long-term unemployment, the effect is, however, imprecisely measured. As no adaptation is observed in the pattern of life satisfaction for the long-term unemployed, it does make sense that no unanticipated adaptation is detected 9 The finding fits recent evidence that the unemployed are overly optimistic regarding how quickly they will find work (Spinnewijn 2014).

\section{Extensions}

\subsection{Learning}

While individual prediction errors are no surprise given the forecast horizon of five years, systematic average errors are not easy to reconcile with standard assumptions about human decisionmaking according to rational choice theory. In particular, we would expect individuals to quickly realize, for example, that they underestimate adaptation processes 10 However, a large body of literature suggests that learning is a complex process, and does not necessarily lead to overcoming mispredictions. Kahneman (2011) offers an excellent account of the difficulties in learning when different mental processes affect judgment and behaviour. In particular, learning is often based on the recollection of past feelings. This recollection is prone to misperceptions though.

\footnotetext{
${ }^{9} \mathrm{~A}$ comparison of the patterns in life satisfaction of all the people who become unemployed and those who remain unemployed for at least five years further reveals that both groups suffer similarly low levels of life satisfaction when unemployed. This is consistent with Gielen and van Ours (2014) who do not observe a link between low life satisfaction and the speed of finding a new job.

10 Ubel et al. (2005) report findings of experiments which suggest that asking people to reflect on adaptation is sufficient to reduce systematic errors in affective forecasts with respect to disability or living in a better climate.
} 
People reflect on specific moments from the past or access generalizations about likely emotions in a particular type of situation (for a discussion, see Robinson and Clore 2002). The more memorable moments of an experience disproportionately affect retrospective assessments of feelings. What counts as "more memorable" tends to be the most intense moment (peak) and the last moment (end) of an emotional event (Kahneman, 2003), 11 Schwarz and Xu (2011) similarly argue that the reconstruction of past feelings draws on the same lay theories that inform choices. As a result, people fail to notice the errors of their predictions as reconstructed memory confirms their erroneous predictions.

In the current context, learning is additionally hampered since people experience many of these events only once in their life and thus have to base their forecasts on their experience of other events. Some people, however, marry or experience a spell of unemployment more than once. It is therefore possible to study whether the prediction errors of experienced individuals are smaller than those of people without prior experience, i.e., people who marry or experience unemployment for the first time.

We explore the aspect of learning from repeated experience by drawing on complementary spell data in the SOEP 12 We identify whether people have experienced marriage or unemployment at least once before they entered the panel. This allows us to split the analysis between those people for whom the first event observed in the sample period is also the first event in their life and those who have already experienced such an event at least once in their lifetime at a time before they were part of the surveys. As in the previous extension, we estimate the effects for the two groups in the same regression in order to assure that the same observations form the reference. Of the 1,769 individuals who we observe within the first year after their marriage, 173 have already been married earlier in their life. For unemployment, we have 665 people who had previously experienced unemployment, and 2,564 people who are unemployed for the first time.

Figures 7 and 8 present the results. The comparison for marriage suggests that people who were previously married at least once adapt less to marriage, and that, on average, their prediction error is smaller by 0.258 points. As there is a limited number of observations to identify this latter prediction error, the small point estimate comes with a large standard error. Similarly, people who have previously experienced unemployment, make a smaller prediction error, on average, after experiencing the event than people who find themselves in this situation for the first time. The difference in the errors amounts to 0.089 points. However, this difference is not

\footnotetext{
${ }^{11} \mathrm{~A}$ more fundamental reason for a person's limited learning capacity might lie in the functionality of utility misprediction in the evolutionary process. Rayo and Becker (2007), for example, model how humans' utility functions formed in order to motivate striving for improvements or more generally to maximize success in genetic replication. Their model rationalizes that people neglect adaptation (described as self-inflicted externality). Whether this utility function with an inbuilt prediction error is still helpful in today's world in guaranteeing an optimal mix between experienced utility and motivation for success in society is an open question though.

${ }^{12}$ In the spell data files, any changes in the marital or the employment status are documented for every person in the sample from the age of 16 onwards. To generate this data, people are asked retrospectively to indicate any status changes up to the year of their first interview. Any changes from then on are directly updated with the information derived from the interviews. We make use of the spell datasets biomarsy for the documentation of the marital status and pbiospe for the recording of the unemployment spells.
} 
statistically significant. There is thus some evidence (though statistically weak) that people learn from repeated life events and then apply this knowledge to their future forecasts of subjective well-being, despite the imponderability of looking through processes of adaptation.

[Figures 7 and 8 about here]

\subsection{Exogenous Event: Layoff due to Plant Closure}

So far, we assumed that the occurrence of an event in people's life is independent of how rosy they see their future. However, even if this is not the case, it does not per se pose a problem for our identification strategy. As long as people's more or less optimistic outlook is a stable trait, it is taken into account in our estimation approach with individual fixed effects. For example, in the case of marriage, overly optimistic people might be more likely to marry. This is taken into account by allowing predicted life satisfaction to be individually higher. The evidence indicates that even with this flexible strategy, being in the new state of marriage is related to a prediction error.

However, there might be changes in people's prospects making them gloomy and affecting both their prediction of future well-being as well as their performance, for example, on the labour market. Thus, if momentarily pessimistic people self-select into unemployment (either voluntarily or due to a dismissal), the negative prediction error for newly unemployed people might reflect a selection effect. To address this, we focus on layoffs due to plant closure as an exogenous source of unemployment (see Kassenboehmer and Haisken-DeNew 2009 for an application of this strategy to measure the effect of unemployment on life satisfaction). In contrast to the study of general job loss, we are thereby able to capture an effect for unemployment on the prediction of future well-being that is closer to a causal interpretation.

For the empirical analysis, we build on the same sample as in our main estimation for unemployment before. However, we additionally restrict it to those incidences of unemployment that are due to plant closure. For the years 1999 and 2000, this information is not available so that we have to exclude people who experience a transition into unemployment during this period. This leaves us with 359 individuals who become unemployed due to plant closure whereof 210 remain in the sample for at least five years ${ }^{13}$

Figure 9 presents the results 14 A similar picture emerges as in the previous estimates on unemployment in general. While individuals anticipate some adjustment, they underestimate the degree to which they regain their initial satisfaction level after being confronted with the negative shock. The highly significant prediction error amounts to 0.502 points with a standard

\footnotetext{
${ }^{13}$ The final sample consists of 109,172 observations including those people who are currently working but who are at risk of experiencing a job loss.

${ }^{14}$ Estimation outputs are available on request.
} 
error of $0.170(\mathrm{p}$-value $=2.96)$. This is more than twice the size of the prediction error estimated for all the people who become unemployed irrespective of the source of their status change. This suggests that for the event of unemployment, the prediction bias cannot be explained by self-selection of overly pessimistic people into unemployment.

[Figure 9 about here]

\section{Concluding Remarks}

Optimal decision making in economics requires that people in expectations make appropriate assessments of the utility consequences of their decisions. This also holds when people think of their reactions in response to changes in circumstances due to major life events. The latter involves predictions about future well-being what might be a challenge. In fact, while many studies report well-being profiles that indicate considerable adaptation to altered life circumstances, it is a rather open issue whether people correctly foresee such processes of adjustment. If systematic biases occur, suboptimal decisions leading to lower levels of individual welfare may result. An analysis of people's well-being predictions after major life events thus contributes from a behavioural and welfare economic perspective to a better understanding of the complex evaluations and decisions individuals face throughout their lives.

In the present study, we assess people's ability to accurately predict their future well-being in response to the loss of a partner, marriage, unemployment, and the experience of disability. To this end, we compare individuals' reports of predicted subjective well-being with the actual realizations later on. Specifically, we confront patterns in reported life satisfaction around major life events with a noncontextual prediction five years into the future for the same measure of life satisfaction. Our empirical strategy thus combines approaches used in the social sciences to investigate adaptation with regard to subjective well-being with approaches used primarily in the psychological literature on affective forecasting.

The empirical findings based on individual panel data for Germany (SOEP) reveal systematic prediction errors. While people are overly pessimistic after experiencing widowhood, unemployment or long-term disability, they are overly optimistic after getting married. In the case of widowhood and disability, large effects from underestimating adjustment possibilities are also measured when the sample is restricted to people who maintain their status as widowed or disabled. As these people cannot have been overly pessimistic regarding the change of their adverse status, the respective prediction errors are likely to be the result of their failure to consider adaptation. There is thus some smoking-gun evidence that the prediction errors are at least partly driven by not fully anticipated adaptation.

Overall, our study reveals that people are susceptible to misprediction after the experience of major changes in their lives. The results back the argument of the skeptics of pure rational 
choice who assert that people's decision-making is potentially biased by mispredicted future well-being. From a welfare perspective, this is particularly important with regard to behaviour that has long-term consequences, e.g., in the case of actions that are difficult to revoke. A case in point is a legally binding commitment like marriage. Moreover, misprediction seems most pronounced if people are likely to experience adaptation. This is in line with the evidence related to a projection bias as proposed by Loewenstein et al. (2003). They model individual decision-making when people systematically underestimate the magnitude of the changes in their tastes what, in turn, can lead to misguided consumption patterns. Moreover, if there are asymmetries regarding the degree of misprediction for different circumstances or consumption goods, people may accrue lower individual welfare due to the misallocation of time, effort and money across alternatives. For example, if people overrate the positive impact of income (or the related purchase of a durable good such as a house), they might invest too much time in accumulating income and wealth relative to enjoying leisure.

In order to derive further implications, future research has to deal with some challenges. First, the degree to which our findings are transferable to predictions involved in economic choices remains open. With marriage, we only consider one event that clearly captures a choice while the other events capture shocks involving only to a limited extent immediate decision-making. Still, if people mispredict the long-term consequences of changing circumstances, it is likely to be relevant for any related behaviour that is based on expectations. Second, the generalisation of the findings is limited to the extent that choices do not rely on predicted subjective well-being. However, even if predicted subjective well-being does not entirely reflect predicted decision utility as some recent studies indicate (Benjamin et al. 2014, 2012), observed choices of people might be distorted insofar as subjective well-being is an argument in people's utility function. Third, it is not at all straightforward to derive normative implications, as prediction errors might not be detrimental per se. In certain cases, the failure to foresee adaptation might indeed lead to beneficial outcomes, for example, when people are prevented from risky health behavior. A more fundamental argument might even link prediction errors to advantages in the evolutionary process (e.g., Rayo and Becker 2007). Finally, it is crucial that future research analyses the conditions under which prediction errors are more or less pronounced. To the extent these challenges are met in the future and we cannot sustain the assumption that people accurately predict the utility they accrue from alternative choice options, economists must attempt incorporating utility misprediction into economic analysis. 


\section{References}

Benjamin, D. J., O. Heffetz, M. S. Kimball, and N. Szembrot (2014). Beyond Happiness and Satisfaction: Toward Well-Being Indices Based on Stated Preference. American Economic Review 104(9), 2698-2735.

Benjamin, D. J., M. S. Kimball, O. Heffetz, and A. Rees-Jones (2012). What Do You Think Would Make You Happier? What Do You Think You Would Choose? American Economic Review 102(5), 2083-2110.

Bertrand, M., E. Duflo, and S. Mullainathan (2004). How Much Should We Trust DifferencesIn-Differences Estimates? Quarterly Journal of Economics 119(1), 249-275.

Brickman, P. and D. T. Campbell (1971). Hedonic Relativism and Planning the Good Science. In M. H. Appley (Ed.), Adaptation-Level Theory, pp. 287-302. New York: Academic Press.

Brickman, P., D. Coates, and R. Janoff-Bulman (1978). Lottery Winners and Accident Victims: Is Happiness Relative? Journal of Personality and Social Psychology 36(8), 917-927.

Clark, A. E., E. Diener, Y. Georgellis, and R. E. Lucas (2008). Lags and Leads in Life Satisfaction: A Test of the Baseline Hypothesis. Economic Journal 118(529), F222-F243.

Clark, A. E. and Y. Georgellis (2013). Back to Baseline in Britain: Adaptation in the British Household Panel Survey. Economica 80(319), 496-512.

Frederick, S. and G. Loewenstein (1999). Hedonic Adaptation. In D. Kahneman, E. Diener, and N. Schwarz (Eds.), Well-being: Foundations of Hedonic Psychology, pp. 302-329. New York: Russell Sage Foundation.

Frey, B. S. and A. Stutzer (2006). Mispredicting Utility and the Political Process. In E. J. McCaffery and J. Slemrod (Eds.), Behavioral Public Finance, pp. 113-140. New York: Russell Sage Foundation.

Frey, B. S. and A. Stutzer (2014). Economic Consequences of Mispredicting Utility. Journal of Happiness Studies 15(4), 937-956.

Frijters, P., H. Greenwell, J. P. Haisken-DeNew, and M. A. Shields (2009). How Well Do Individuals Predict Their Future Life Satisfaction? Evidence from Panel Data Following a Nationwide Exogenous Shock. Canadian Journal of Economics 42(4), 1326-1346.

Frijters, P., D. W. Johnston, and M. A. Shields (2011). Life Satisfaction Dynamics with Quarterly Life Event Data. Scandinavian Journal of Economics 113(1), 190-211.

Gielen, A. C. and J. C. van Ours (2014). Unhappiness and Job Finding. Economica 81(323), $544-565$.

Gilbert, D. T., E. C. Pinel, T. D. Wilson, S. J. Blumberg, and T. P. Wheatley (1998). Immune Neglect: A Source of Durability Bias in Affective Forecasting. Journal of Personality and Social Psychology 75(3), 617-638.

Hsee, C. K., Y. Rottenstreich, and A. Stutzer (2012). Suboptimal Choices and the Need for Experienced Individual Well-Being in Economic Analysis. International Journal of Happiness and Development 1(1), 63-85. 
Kahneman, D. (2003). Maps of Bounded Rationality: Psychology for Behavioral Economics. American Economic Review 93(5), 1449-1475.

Kahneman, D. (2011). Thinking, Fast and Slow. New York: Farrar, Straus and Giroux.

Kahneman, D., A. B. Krueger, D. Schkade, N. Schwarz, and A. A. Stone (2006). Would You Be Happier If You Were Richer? A Focusing Illusion. Science 312(5782), 1908-1910.

Kahneman, D. and R. H. Thaler (2006). Anomalies: Utility Maximization and Experienced Utility. Journal of Economic Perspectives 20(1), 221-234.

Kassenboehmer, S. C. and J. P. Haisken-DeNew (2009). You're Fired! The Causal Negative Effect of Entry Unemployment on Life Satisfaction. Economic Journal 119(536), 448-462.

Lang, F. R., D. Weiss, D. Gerstorf, and G. G. Wagner (2013). Forecasting Life Satisfaction Across Adulthood: Benefits of Seeing a Dark Future? Psychology and Aging 28(1), 249-261.

Lench, H. C., M. A. Safer, and L. J. Levine (2011). Focalism and the Underestimation of Future Emotion: When It's Worse than Imagined. Emotion 11(2), 278.

Levine, L. J., H. C. Lench, R. L. Kaplan, and M. A. Safer (2012). Accuracy and Artifact: Reexamining the Intensity Bias in Affective Forecasting. Journal of Personality and Social Psychology 103(4), 584-605.

Levine, L. J., H. C. Lench, R. L. Kaplan, and M. A. Safer (2013). Like Schrödinger's Cat, the Impact Bias Is Both Dead and Alive: Reply to Wilson and Gilbert (2013). Journal of Personality and Social Psychology 105(5), 749-756.

Loewenstein, G., T. O'Donoghue, and M. Rabin (2003). Projection Bias in Predicting Future Utility. Quarterly Journal of Economics 118(4), 1209-1248.

Loewenstein, G. and D. Schkade (1999). Wouldn’t It Be Nice? Predicting Future Feelings. In D. Kahneman, E. Diener, and N. Schwarz (Eds.), Well-being: Foundations of Hedonic Psychology, pp. 85-105. New York: Russell Sage Foundation.

Lucas, R. E. (2007). Adaptation and the Set-Point Model of Subjective Well-Being: Does Happiness Change After Major Life Events? Current Directions in Psychological Science 16(2), $75-79$.

Lucas, R. E., A. E. Clark, Y. Georgellis, and E. Diener (2003). Reexamining Adaptation and the Set Point Model of Happiness: Reactions to Changes in Marital Status. Journal of Personality and Social Psychology 84(3), 527-539.

Luhmann, M., W. Hofmann, M. Eid, and R. E. Lucas (2012). Subjective Well-Being and Adaptation to Life Events: A Meta-Analysis. Journal of Personality and Social Psychology 102(3), 592-615.

Muth, J. F. (1961). Rational Expectations and the Theory of Price Movements. Econometrica 29(3), 315-335.

Oswald, A. J. and N. Powdthavee (2008). Does Happiness Adapt? A Longitudinal Study of Disability with Implications for Economists and Judges. Journal of Public Economics 92(5-6), 1061-1077. 
Powdthavee, N. and A. Stutzer (2014). Economic Approaches to Understanding Change in Happiness. In K. M. Sheldon and R. E. Lucas (Eds.), Stability of Happiness: Theories and Evidence on Whether Happiness Can Change, pp. 219-244. Oxford: Academic Press.

Rayo, L. and G. S. Becker (2007). Evolutionary Efficiency and Happiness. Journal of Political Economy 115(2), 302-337.

Robinson, M. D. and G. L. Clore (2002). Belief and Feeling: Evidence for an Accessibility Model of Emotional Self-Report. Psychological Bulletin 128(6), 934-960.

Schwandt, H. (2013). Unmet Aspirations as an Explanation for the Age U-shape in Human Wellbeing. CEP Discussion Paper No 1229. CEP: London.

Schwarz, N. and J. Xu (2011). Why Don't We Learn from Poor Choices? The Consistency of Expectation, Choice, and Memory Clouds the Lessons of Experience. Journal of Consumer Psychology 21(2), 142-145.

Sharot, T. (2011). The Optimism Bias: A Tour of the Irrationally Positive Brain. New York: Random House.

Sheldon, K. M. and R. E. Lucas (Eds.) (2014). Stability of Happiness: Theories and Evidence on Whether Happiness Can Change. Oxford: Academic Press.

Spinnewijn, J. (2014). Unemployed but Optimistic: Optimal Insurance Design with Biased Beliefs. Journal of the European Economic Association, forthcoming.

Stutzer, A. and B. S. Frey (2006). Does Marriage Make People Happy, or Do Happy People Get Married? The Journal of Socio-Economics 35(2), 326-347.

Ubel, P. A., G. Loewenstein, and C. Jepson (2005). Disability and Sunshine: Can Hedonic Predictions Be Improved by Drawing Attention to Focusing Illusions or Emotional Adaptation? Journal of Experimental Psychology: Applied 11(2), 111-123.

Weesie, J. (1999). Seemlingly Unrelated Estimation and the Cluster-Adjusted Sandwich Estimator. Stata Technical Bulletin 9(52), 231-248.

Wilson, T. D. and D. T. Gilbert (2003). Affective Forecasting. Advances in Experimental Social Psychology 35, 345-411.

Wilson, T. D. and D. T. Gilbert (2013). The Impact Bias Is Alive and Well. Journal of Personality and Social Psychology 105(5), 740-748. 
Table 1: Number of observations before and after the event

\begin{tabular}{lcccc}
\hline \hline & Widowhood & Marriage & Unemployment & Disability \\
\hline Before the event & & & & \\
3 years and more & 4,194 & 6,022 & 8,758 & 7,021 \\
3-2 years & 551 & 1,319 & 2,256 & 969 \\
2-1 years & 592 & 1,579 & 2,682 & 1,000 \\
1-0 years & 607 & 1,823 & 3,150 & 1,041 \\
After the event & & & & \\
0-1 year & 564 & 1,769 & 3,229 & 1,001 \\
1-2 years & 521 & 1,605 & 2,971 & 831 \\
2-3 years & 468 & 1,467 & 2,475 & 706 \\
3-4 years & 417 & 1,306 & 2,142 & 594 \\
4-5 years & 365 & 1,205 & 1,836 & 515 \\
5-6 years & 358 & 1,041 & 1,742 & 431 \\
6 years or more & 1,771 & 4,949 & 8,659 & 1,737 \\
\hline Total & 10,408 & 24,085 & 39,900 & 15,846 \\
\hline \hline
\end{tabular}

Data source: SOEP. 


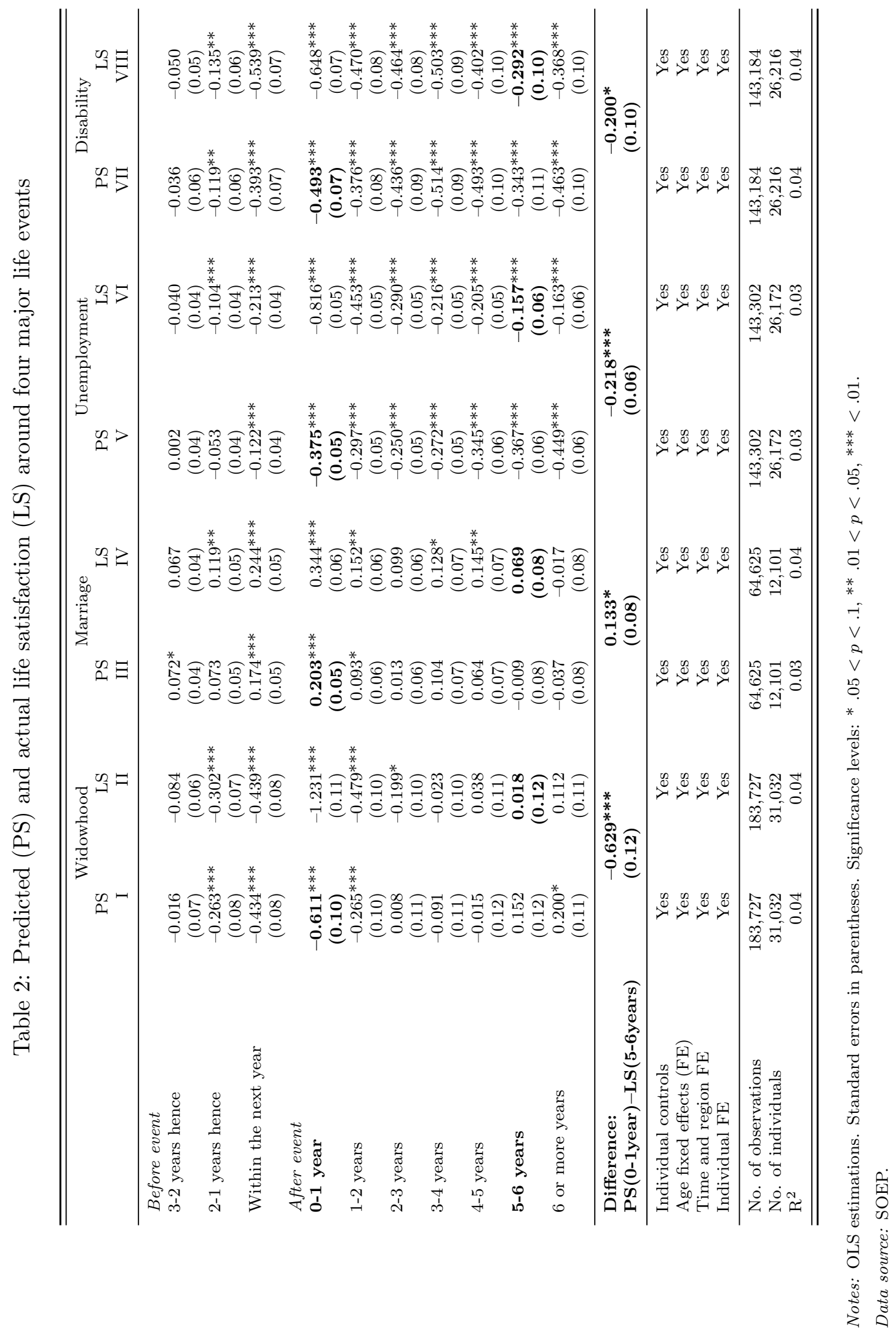


Figure 1: Patterns in mean actual and predicted life satisfaction around life events


Actual life satisfaction

\section{Predicted life satisfaction}

Notes: Sample sizes are according to the numbers presented in Table 1.

Data source: SOEP. 
Figure 2: Distributions of prediction errors after life events
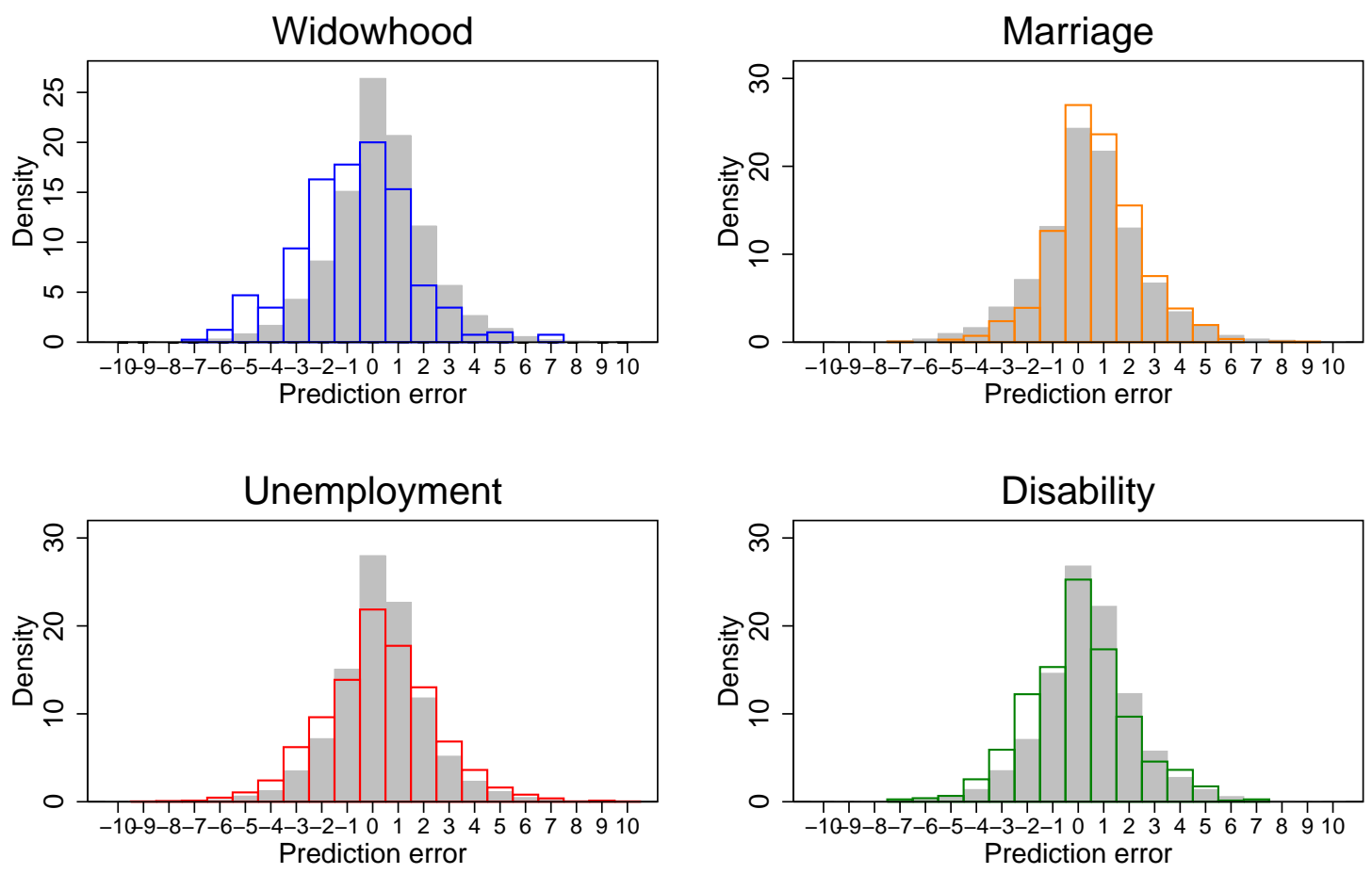

Full sample

1st year after experiencing the event

Notes: Full sample refers to all the observations included in the regressions in Table 2 except the individuals who experience an event. The coloured distribution refers to only those observations in the first year after the respective event.

Data source: SOEP. 
Figure 3: Estimated patterns in actual and predicted satisfaction around four major life events
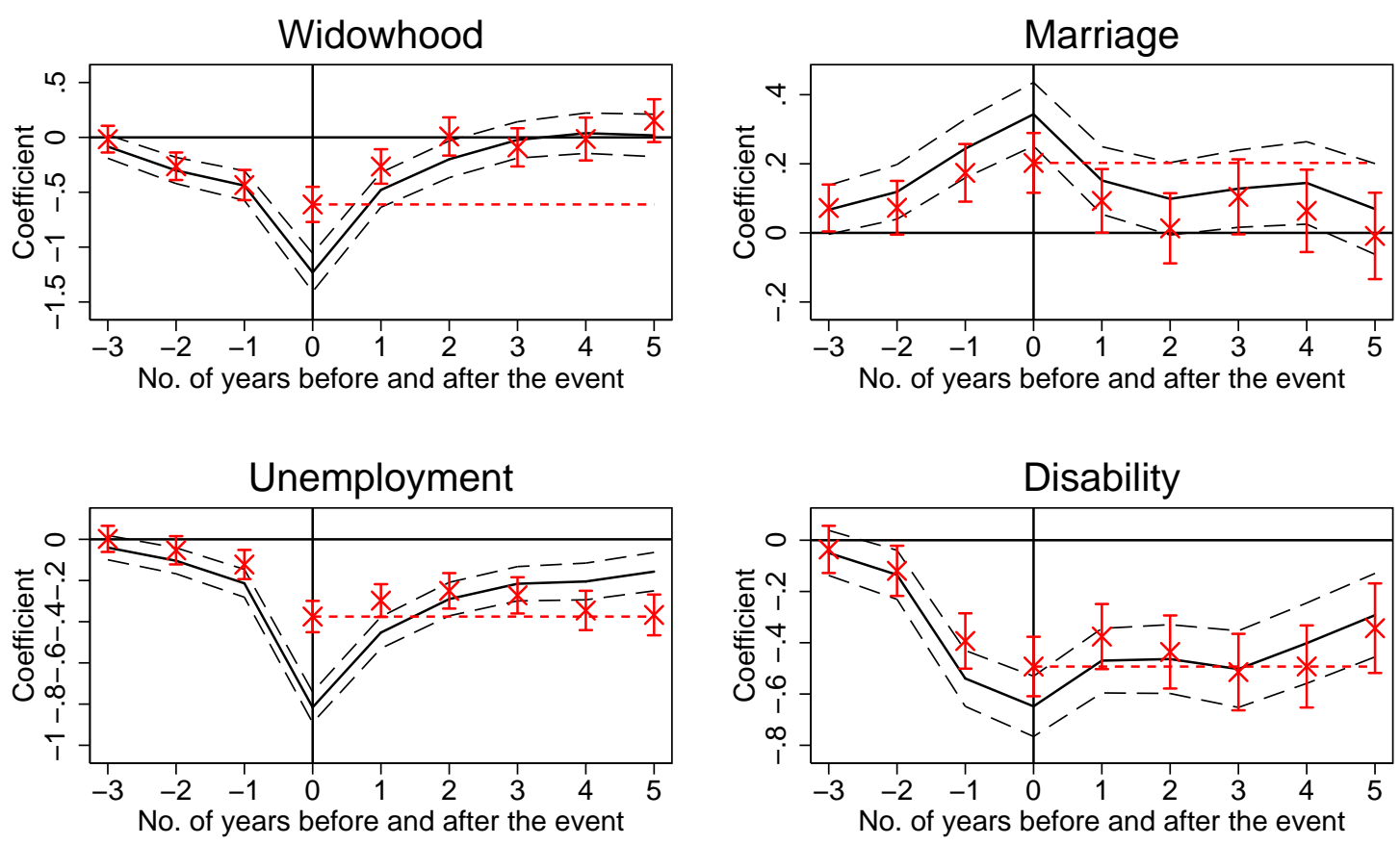

\begin{tabular}{|c|c|c|}
\hline $\begin{array}{l}\text { Change in life satisfaction } \\
-\ldots--90 \% \text { Confidence interval }\end{array}$ & $x$ & $\begin{array}{l}\text { Change in predicted satisfaction } \\
90 \% \text { Confidence interval }\end{array}$ \\
\hline
\end{tabular}

Notes: Based on the estimated coefficients in Table 2. The red dashed line is an auxiliary line that indicates the effect of the event on the expected satisfaction five years after the event. The prediction error is reflected in the difference between the red dashed line and the black solid line (capturing the effect on actual satisfaction) in period 5 .

Data source: SOEP. 
Figure 4: Prediction errors based on alternative samples

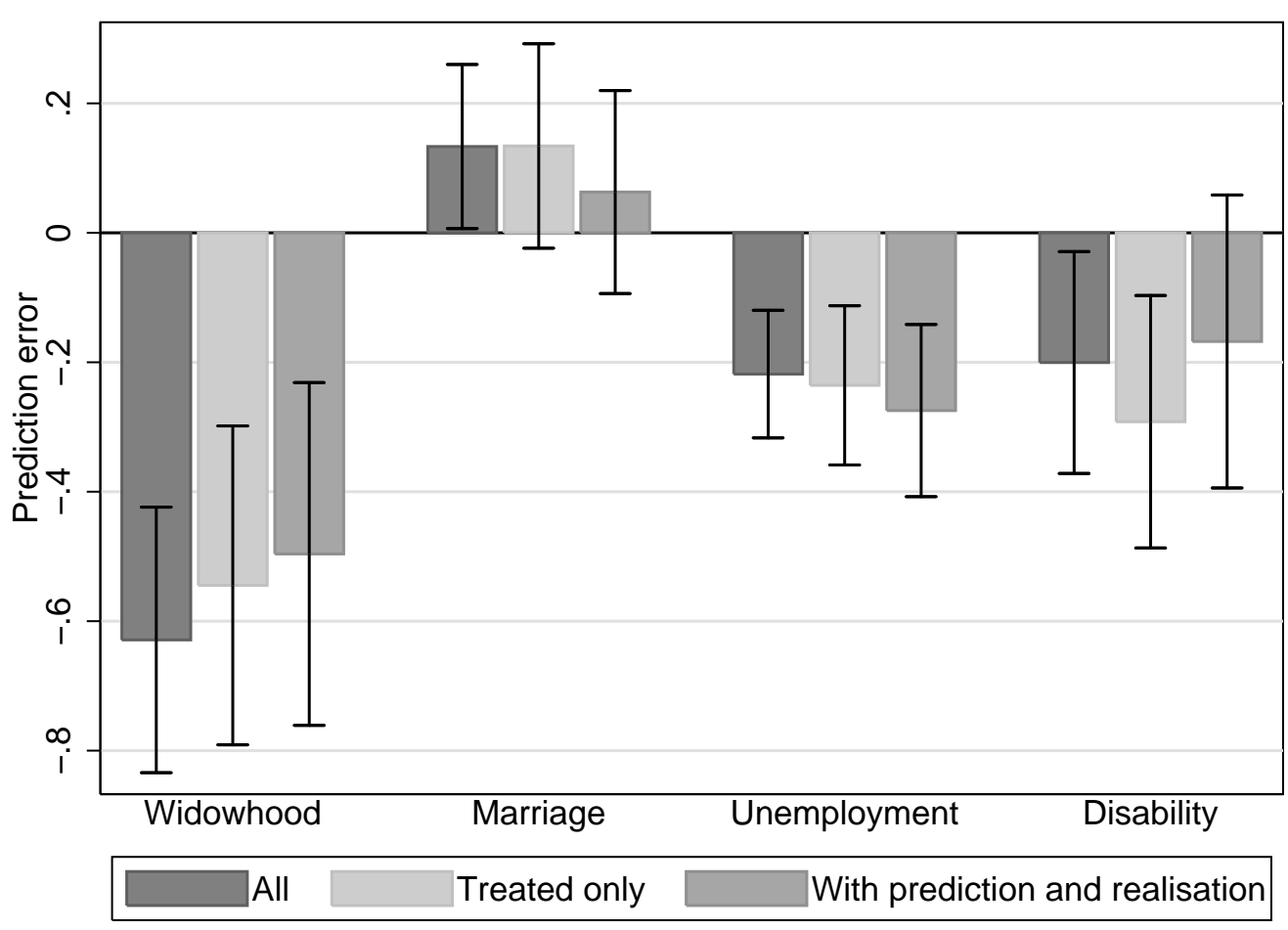

Notes: 90 percent confidence intervals are indicated. The prediction errors for all refer to the estimation results in Table 2. Prediction errors for treated only restrict the samples to people who experienced the event in question. Prediction errors for with prediction and realisation restrict the sample to observations for predictions right after the event that are all matched with the corresponding realisations for the same individuals five years later. 
Figure 5: Estimated patterns in actual and predicted satisfaction for those who remain in the respective status for at least 5 years
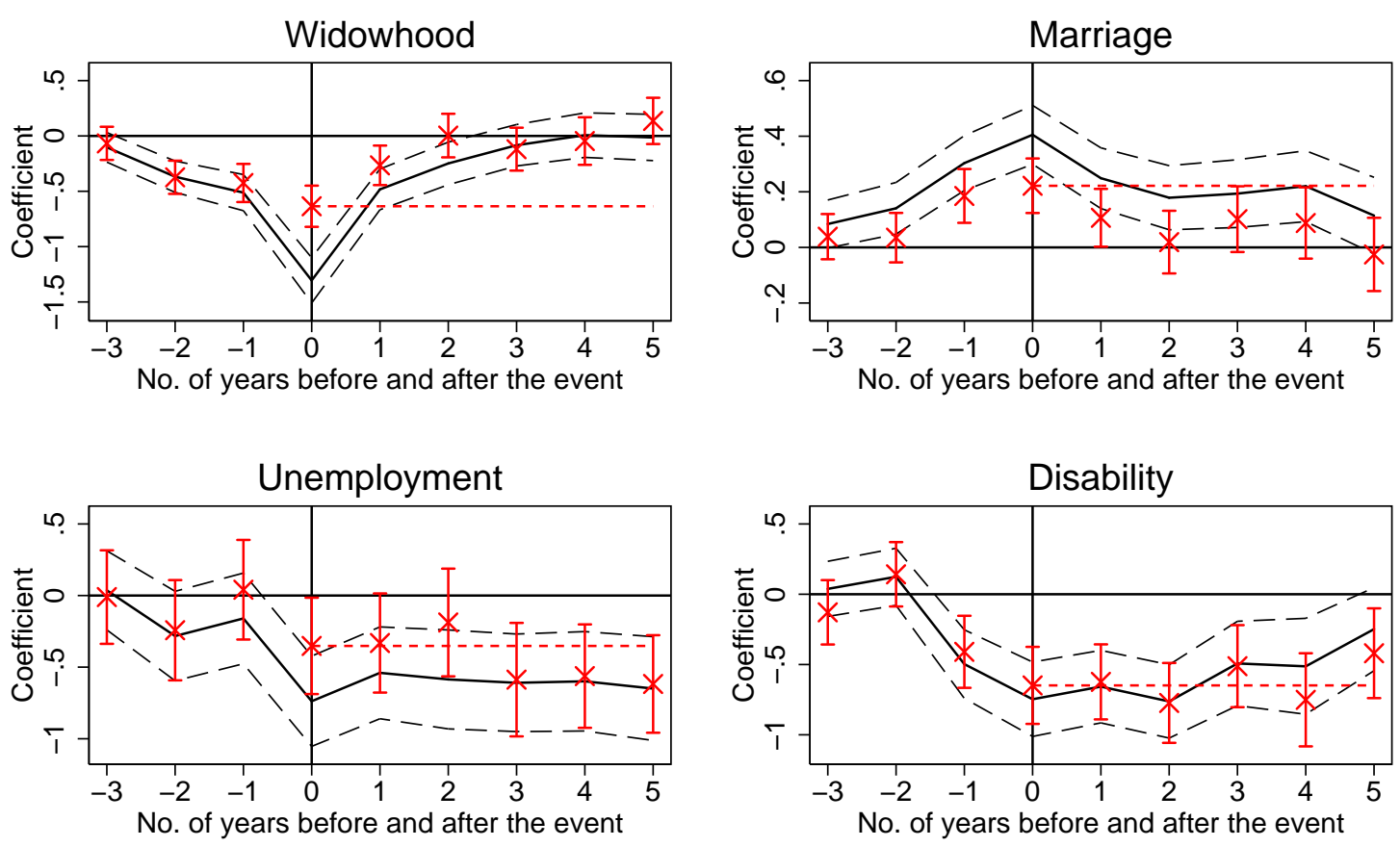

\begin{tabular}{|lll}
\hline- Change in life satisfaction & $\times \quad \begin{array}{l}\text { Change in predicted satisfaction } \\
-----90 \% \text { Confidence interval }\end{array} \quad 90 \%$ Confidence interval
\end{tabular}

Notes: Based on the estimated coefficients in Table A.4. The red dashed line is an auxiliary line that indicates the effect of the event on the expected satisfaction five years after the event. The prediction error is reflected in the difference between the red dashed line and the black solid line (capturing the effect on actual satisfaction) in period 5.

Data source: SOEP. 
Figure 6: Comparison of the prediction errors made by all the people who experience the event and by those who remain in the respective status for at least 5 years

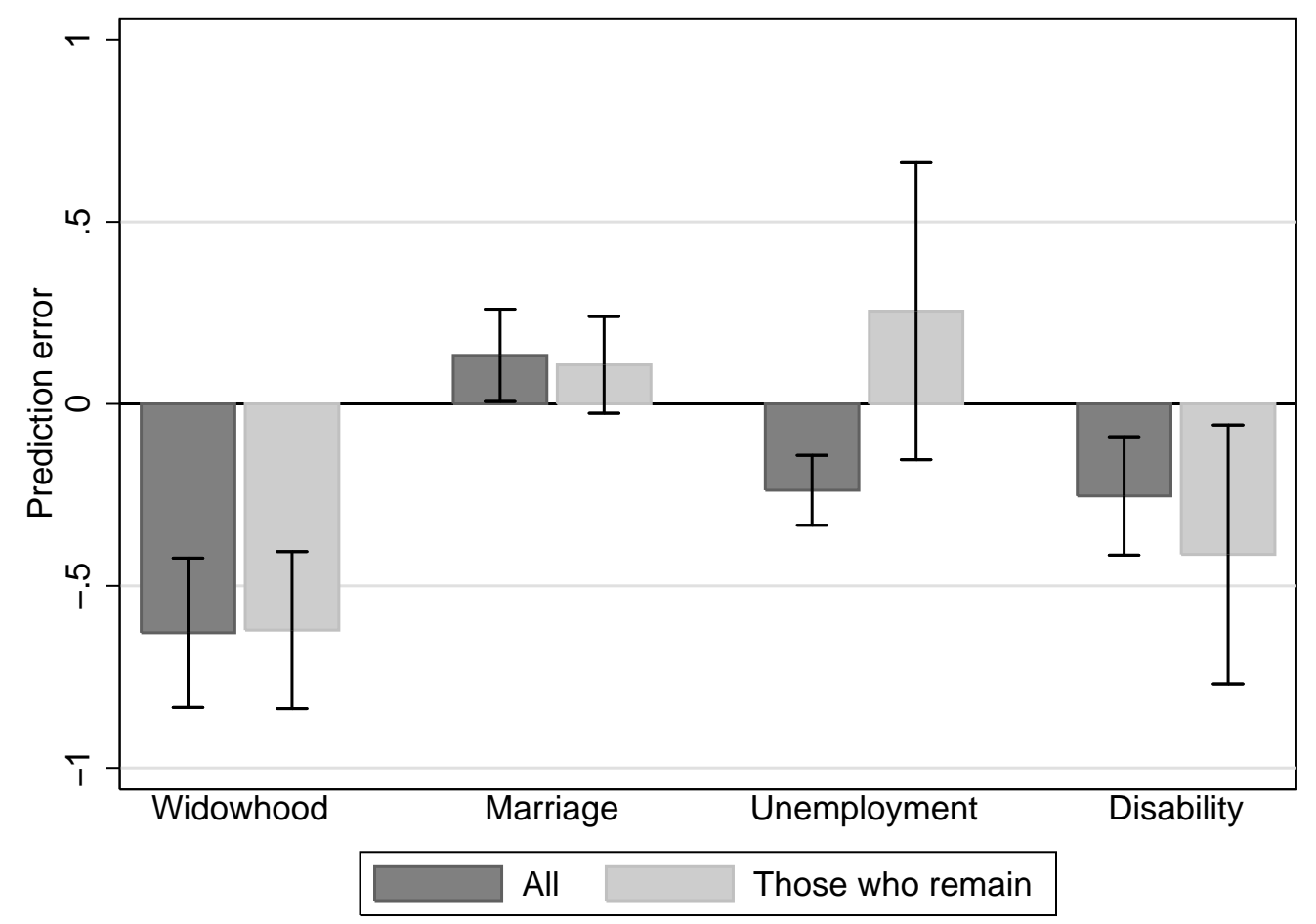

Notes: Based on calculated differences in Table 2 and Table A.4 with 90 percent confidence intervals indicated. 
Figure 7: Estimated patterns in actual and predicted satisfaction for those who experience the event for the first time compared to those who experience it at least for the second time
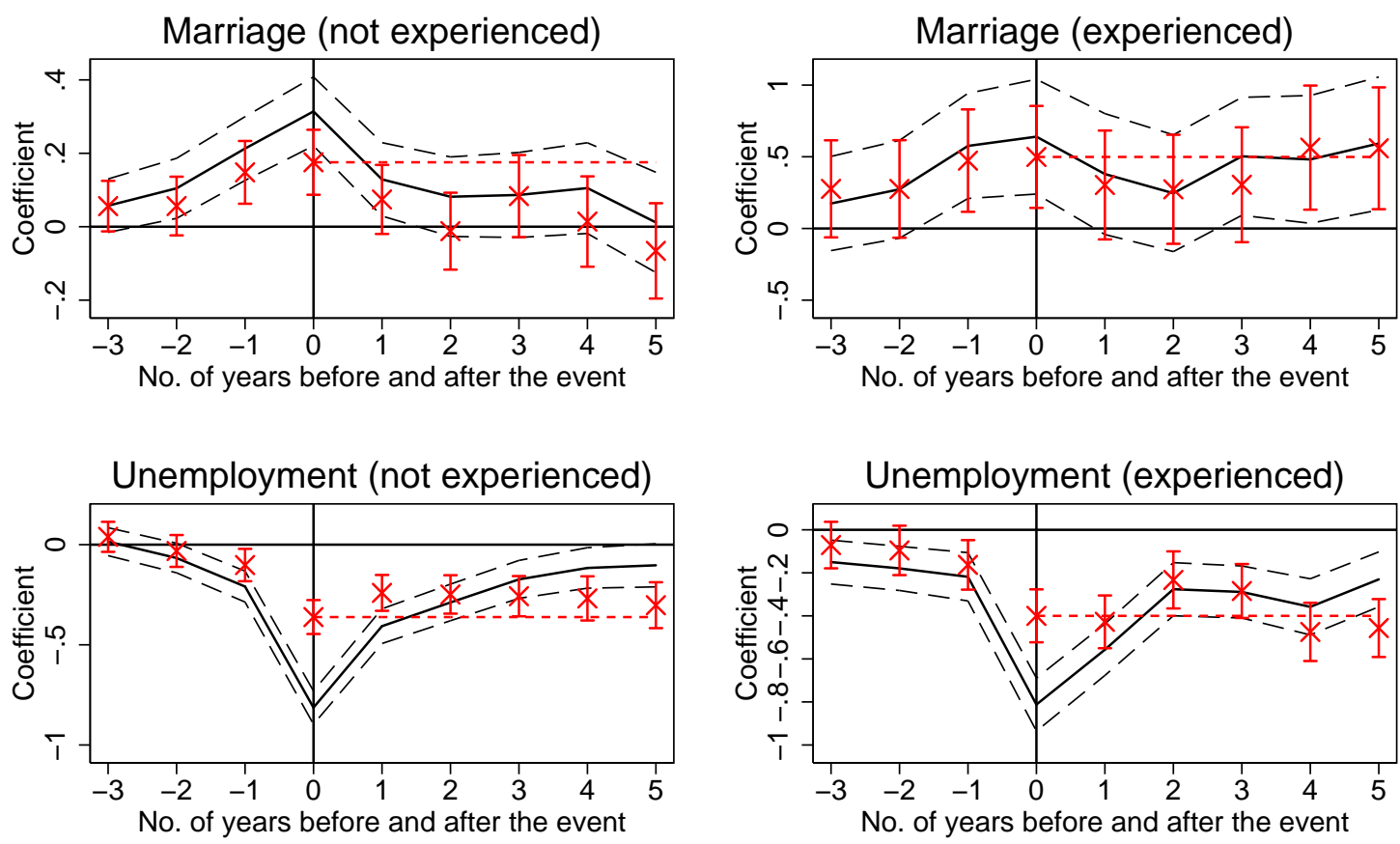



Notes: The red dashed line is an auxiliary line that indicates the effect of the event on the expected satisfaction five years after the event. The prediction error is reflected in the difference between the red dashed line and the black solid line (capturing the effect on actual satisfaction) in period 5 .

Data source: SOEP. 
Figure 8: Comparison of prediction errors between those who experience the event for the first time and those who experience it at least for the second time

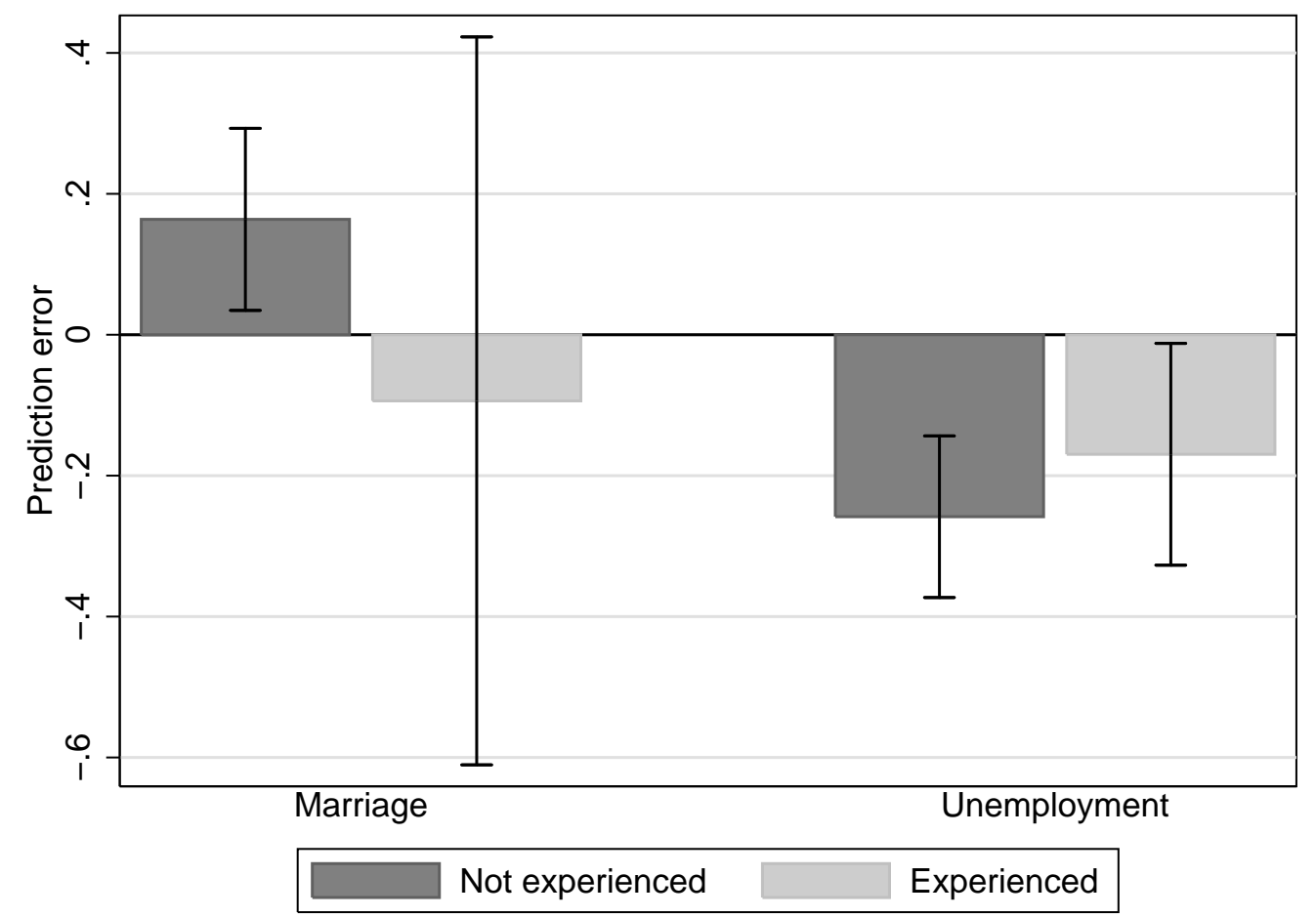

Notes: 90 percent confidence intervals indicated. 
Figure 9: Estimated patterns in actual and predicted satisfaction for those who experience unemployment due to plant closure

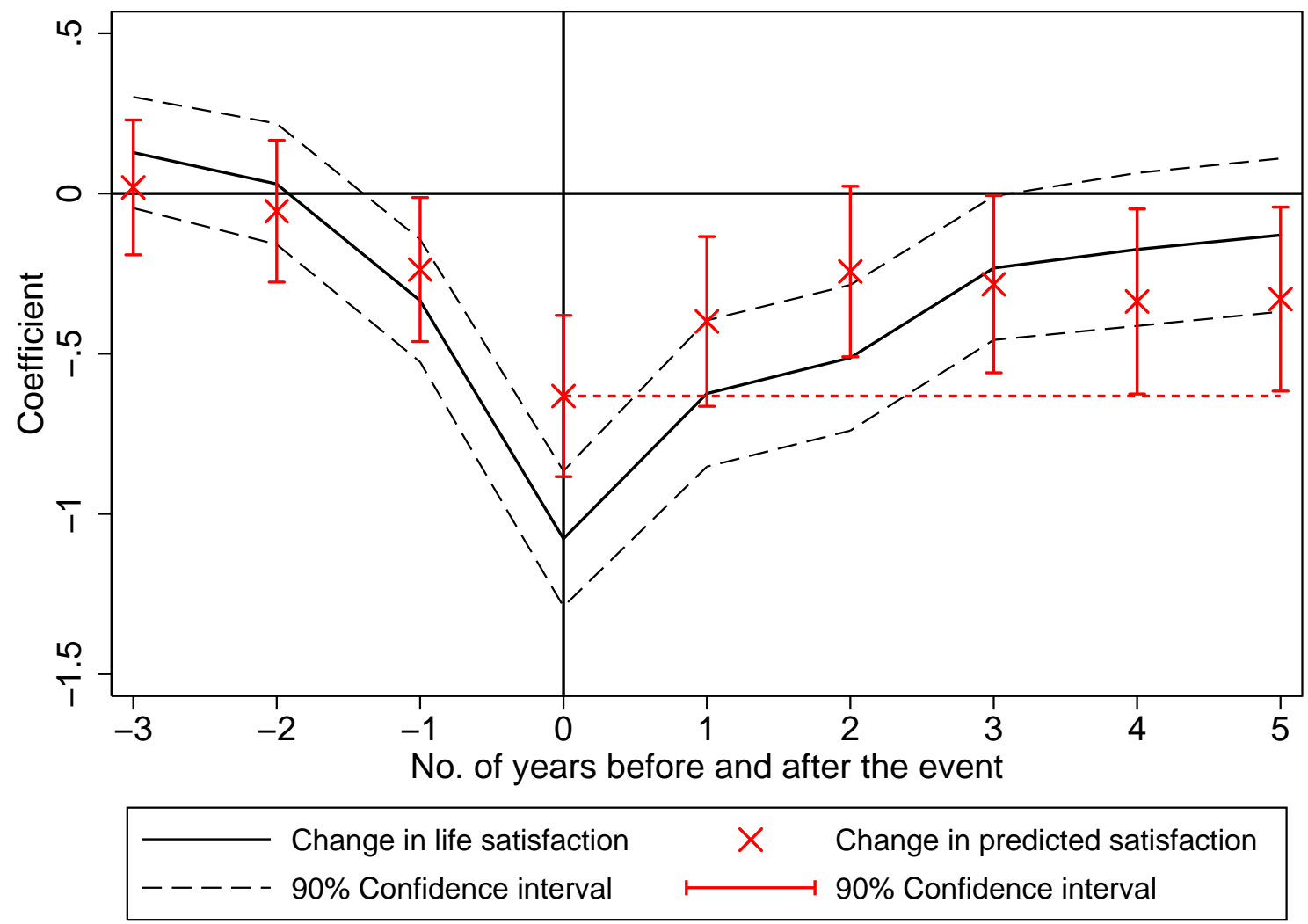

Notes: The red dashed line is an auxiliary line that indicates the effect of the event on the expected satisfaction five years after the event. The prediction error is reflected in the difference between the red dashed line and the black solid line (capturing the effect on actual satisfaction) in period 5 .

Data source: SOEP. 


\section{Appendix}

Table A.1: Descriptive statistics for the sample used to analyse widowhood

\begin{tabular}{lrrrr}
\hline \hline & Mean & Std. dev. & Min. & Max. \\
\hline Life satisfaction & 6.997 & 1.758 & 0 & 10 \\
Predicted life satisfaction in 5 years & 7.029 & 1.915 & 0 & 10 \\
\hline Female & 0.501 & 0.500 & 0 & 1 \\
Age & 44.680 & 16.081 & 17 & 99 \\
Years of schooling & 11.626 & 2.575 & 7 & 18 \\
German & 0.881 & 0.324 & 0 & 1 \\
\hline Single & 0.220 & 0.414 & 0 & 1 \\
Married & 0.715 & 0.451 & 0 & 1 \\
Separated & 0.008 & 0.087 & 0 & 1 \\
Divorced & 0.034 & 0.181 & 0 & 1 \\
Widowed & 0.023 & 0.151 & 0 & 1 \\
\hline Working & 0.613 & 0.487 & 0 & 1 \\
Unemployed & 0.058 & 0.233 & 0 & 1 \\
Not working & 0.135 & 0.341 & 0 & 1 \\
In education & 0.028 & 0.166 & 0 & 1 \\
Maternity leave & 0.019 & 0.135 & 0 & 1 \\
Some work & 0.034 & 0.180 & 0 & 1 \\
Pensioner & 0.114 & 0.318 & 0 & 1 \\
\hline ln(household income after tax) & 10.249 & 0.569 & 0 & 15 \\
No. of children in household & 0.656 & 0.971 & 0 & 10 \\
Size of household & 2.982 & 1.300 & 1 & 15 \\
\hline No. of observations & 183,727 & & & \\
No. of individuals & 31,032 & & & \\
\hline \hline
\end{tabular}

Data source: SOEP. 


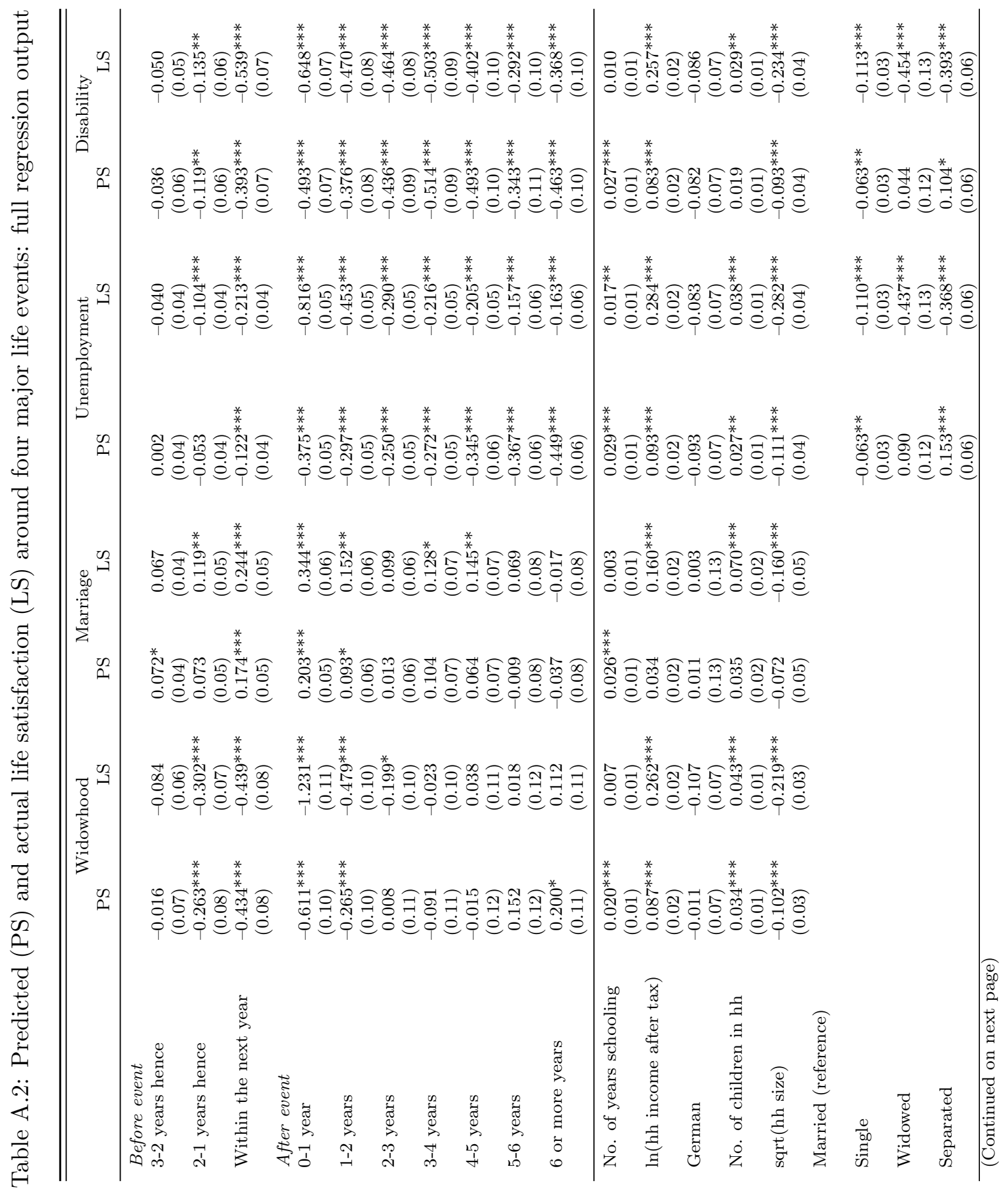




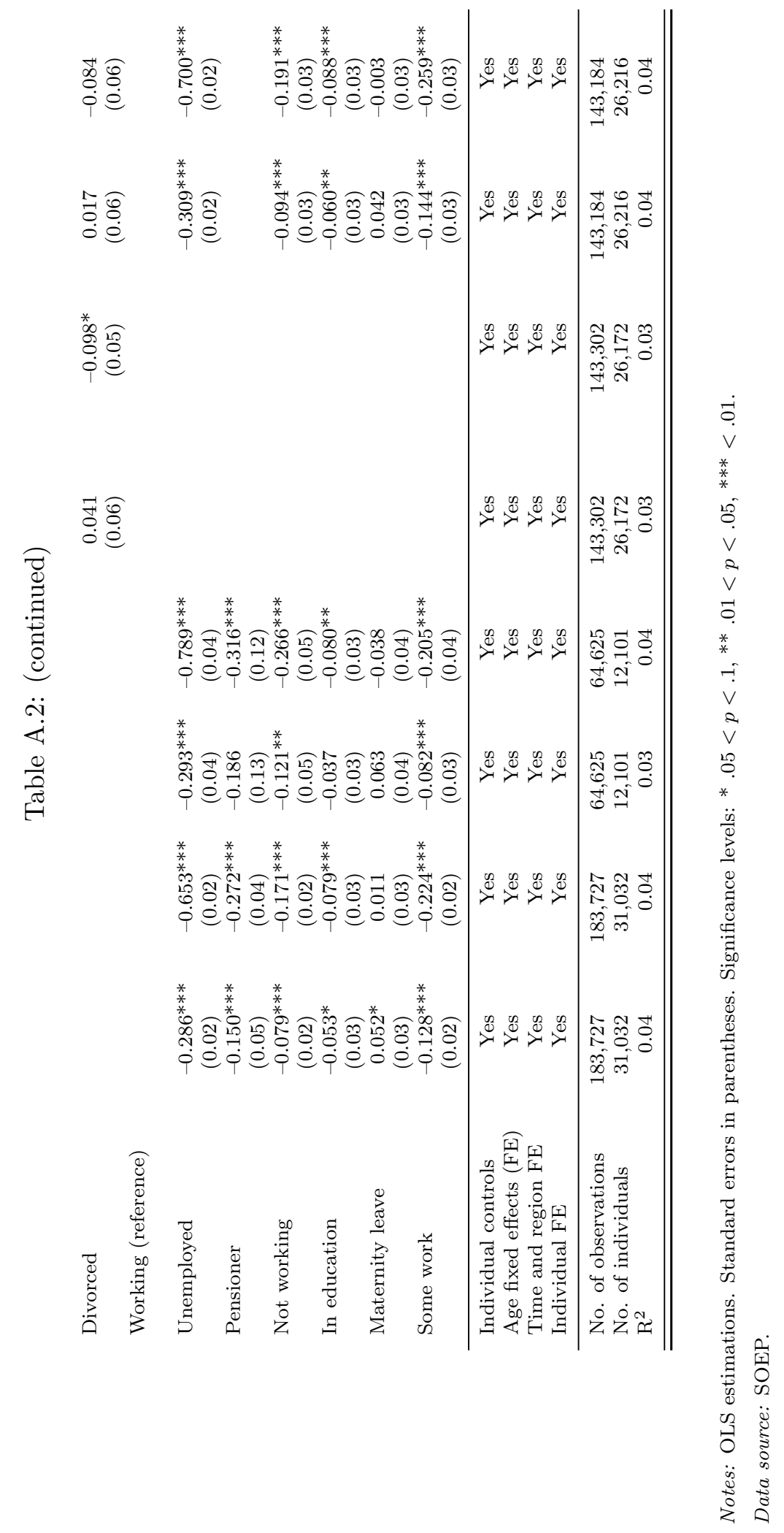


Table A.3: Number of observations before and after the event for those who remain in the respective status for at least 5 years

\begin{tabular}{lcccc}
\hline \hline & Widowhood & Marriage & Unemployment & Disability \\
\hline Before event & & & & \\
3 years and more & 1,493 & 2,337 & 219 & 1,342 \\
3-2 years & 336 & 787 & 67 & 170 \\
2-1 years & 387 & 1,020 & 78 & 184 \\
1-0 years & 401 & 1,195 & 98 & 188 \\
After event & & & & \\
0-1 year & 384 & 1,176 & 102 & 183 \\
1-2 years & 380 & 1,142 & 108 & 166 \\
2-3 years & 363 & 1,123 & 99 & 139 \\
3-4 years & 350 & 1,075 & 90 & 117 \\
4-5 years & 325 & 1,039 & 85 & 103 \\
5-6 years & 340 & 950 & 70 & 90 \\
6 years or more & 1,650 & 826 & 42 & 73 \\
\hline Total & 6,409 & 12,670 & 1,058 & 2,755 \\
\hline \hline
\end{tabular}

Data source: SOEP. 




